\title{
Research on Damping Engagement Methodology in Dynamic Analysis of Isolated Structure
}

\author{
Miao Han $(\mathbb{D}$, Jinwei Jiang $(\mathbb{D}$, Hongkai Du $(\mathbb{D}$, and Sijia Feng $\mathbb{C}$ \\ Beijing University of Civil Engineering and Architecture, Beijing 100044, China \\ Correspondence should be addressed to Hongkai Du; duhongkai@bucea.edu.cn
}

Received 29 December 2020; Revised 1 September 2021; Accepted 2 September 2021; Published 21 September 2021

Academic Editor: Gerardo Silva-Navarro

Copyright (c) 2021 Miao Han et al. This is an open access article distributed under the Creative Commons Attribution License, which permits unrestricted use, distribution, and reproduction in any medium, provided the original work is properly cited.

\begin{abstract}
Damping has a significant influence on the calculation of structural seismic response. In this paper, we compare the commonly used viscous damping (Rayleigh damping $(\mathrm{RD})$ and Caughey damping $(\mathrm{CD})$ ) in combination with the isolated structure test. To avoid the arbitrariness of choosing two reference vibration frequencies in constructing $\mathrm{RD}$, all the combinations of the first several vibration frequencies were calculated. Because the material characteristics of the isolation layer and the superstructure are significantly different and the deformation of the isolation layer is large, we construct nonproportional damping according to these two kinds of damping and make a comparative analysis. Analyzing experimental data, we can obtain the optimal frequency combination of $\mathrm{RD}$ and nonproportional damping during dynamic analysis of the isolated structure, the priority order of choosing damping models. For the calculation of RD, the 1 st modal frequency of the structure should be included, and the $2 \mathrm{nd}$ and 3rd modal frequencies of the nonisolated structure are proposed to calculate the nonproportional damping based on Rayleigh damping (NP-RD) for the three-story frame structure in this paper. RD and nonproportional damping based on Caughey damping (NP-CD) are firstly recommended to be used in the calculation of the isolated structure, followed by NP-RD and then $\mathrm{CD}$.
\end{abstract}

\section{Introduction}

From the perspective of energy, the isolation technology can protect the superstructure by consuming the earthquake energy and reducing its transmission to upper levels. The energy dissipation capacity of a structure is usually recorded as damping, but it is difficult to obtain the damping accurately because of its complex components [1,2]. Methods of damping calculation have been proposed since the 20th century [3-6], which are related to physical characteristics of the structure, the equivalent target, and analysis method of damping [7]. The viscous damping model, i.e., Rayleigh damping, is widely used because of its simple form and convenient mathematical processing [8-11].

Finite element software, such as ABAQUS and ANSYS, usually use Rayleigh damping to measure the energy consumption of the structure. Rayleigh damping $[C]$ is a linear combination of the mass matrix $[M]$ and the stiffness matrix $[K][12]:[C]=a[M]+b[K]$. The mass coefficient $a$ and the stiffness coefficient $b$ are calculated by two frequencies $\left(\omega_{i}\right.$ and $\left.\omega_{j}\right)$ and the corresponding damping ratio [13]. This method will underestimate the damping between $\omega_{i}$ and $\omega_{j}$ and overestimate the damping beyond the range of $\omega_{i}$ and $\omega_{j}$ [14-16]. Many methods have been proposed to calculate the stiffness coefficient and mass coefficient based on the structural dynamic characteristics and ground motion characteristics [17-19]. However, Rayleigh damping is still most widely used because of the inconvenience of other methods. It is very important to find the laws of choosing $\omega_{i}$ and $\omega_{j}$ aright to get more accurate seismic results, as the two frequencies are still selected artificially according to experience of calculation [18].

Caughey damping [20] is called extended Rayleigh damping $[21,22]$. It can be used when multiorder frequencies and damping ratios of a structure are known [23-25]. Research studies mostly focus on the effects of Rayleigh damping and Caughey damping on the calculation of high-rise or long-span structures [26-29], but few are 
about their effects on the dynamic response of isolated structures [10, 30].

The restoring force model, which is derived from the hysteresis curve of component subjected to the reciprocating load, has a significant influence on the dynamic calculation. To reduce the influence of the restoring force model, tests and research studies have been carried out on the mechanical characteristics of the isolation bearing used in this paper [31].

Because of the huge difference of material properties between the isolation layer and the superstructure, nonproportional damping was used in both Rayleigh and Caughey damping [32-34]. In this method, for the two parts of the system, the damping matrix is constructed by Rayleigh damping or Caughey damping and then assembled into the damping matrix of the entire structure $[35,36]$.

Although many scholars have proposed many methods to accurately construct Rayleigh damping, the basic $\mathrm{RD}$ with two frequencies is most frequently applied to structural dynamic calculation in engineering applications and research studies. However, few research studies focused on the frequency selection for $\mathrm{RD}$, which leads to a lack of confidence in the frequency and damping selection during the dynamic numerical calculation. It is also useful to prove the accuracies of different damping models.

Based on the isolated structural tests, this paper analyzes the influence of frequency on damping and the influence of different damping models on the dynamic response of isolated structures.

\section{Experimental and Calculation Description}

2.1. Superstructure. The prototype of the superstructure is a three-story steel moment resistant frame in the seismic area of intensity 8 (according to Chinese code). A middle span was derived and scaled with the similitude law of $1: 6$, as shown in Figure 1. The dimension of the experimental model is $1.3 \mathrm{~m} \times 0.95 \mathrm{~m} \times 0.6 \mathrm{~m}$; No. 10 steel channels (with a dimension of $100 \mathrm{~mm} \times 48 \mathrm{~mm} \times 5.3 \mathrm{~mm} \times 8.5 \mathrm{~mm}$, Chinese code) were utilized as beams; and $\mathrm{L} 50 \mathrm{~mm} \times 50 \mathrm{~mm} \times 5 \mathrm{~mm}$ steel angles were used as columns. The theoretical value of interstory stiffness is $4982 \mathrm{~N} / \mathrm{mm}$. According to the similitude law, the material density of specimen should be 6 times of the prototype, so complementary artificial masses were placed to make up for the insufficient density. The total weight of the model with the masses was 5.29 tons, i.e., 1.32 tons for every story.

2.2. Isolation Bearing. Four laminated rubber bearings were installed in the isolation layer, and the specific dimension and parameters are shown in Figure 2 and Table 1. The maximum deformation is less than $50 \%$ shear strain in all the cases, which represents the isolation bearings were still in the elasticity stage with the shear stiffness of $165 \mathrm{~N} / \mathrm{mm}$ according the pressure-shear tests of the isolation bearings.

2.3. Testing. Ground motions with different spectral characteristics were selected from site conditions II and III, as shown in Table 2 . The time interval was scaled by $1 / \sqrt{6}$ according to the similitude law. The PGA was scaled to $0.07 \mathrm{~g}$ and $0.20 \mathrm{~g}$ for elastic designing (i.e., 0.3 times of Design of Basis Earthquake (DBE) and DBE in US) according to Chinese code. A total of 12 shaking table tests were conducted, as shown in Table 3.

2.4. Numerical Model and Calculation Method. A multidegree-of-freedom calculation model was established based on the experimental model in order to verify the effectiveness of the damping model. The calculation model is a story shear model with the floor mass of 1.32 tons, the interstory stiffness of $4982 \mathrm{~N} / \mathrm{mm}$, and the isolation stiffness of $660 \mathrm{~N} / \mathrm{mm}$. Four damping coefficient construction methods, i.e., Rayleigh damping (RD), Caughey damping (CD), nonproportional damping based on Rayleigh and Caughey damping, were examined based on the frequencies and damping ratios identified by the experimental system. The Wilson- $\theta$ method was used for the MDOF model calculation. The ground motions used to excite the model were from the shaking table collected by using an accelerometer.

2.5. System Identification. System identification tests were performed to identify the structural and dynamic properties of the scaled fixed base (nonisolated) and isolated base building model before and after every main test. The system identification tests included white noise (15 tests) and sine sweep ( 2 tests, $5 \mathrm{x}$ frequency and $6 \mathrm{x}$ frequency). The frequency of the systems is shown in Table 4. The theoretical frequencies and errors of the two systems are also shown in Table 4, which indicate that they match well.

Pull-back tests were performed to identify the viscous damping ratio of the systems $[37,38]$, which show that the damping ratio of the isolated structure is 0.0435 and that of the nonisolated structure is 0.00134 . The damping ratios are utilized for the other vibration modes of systems in this research, since it is hard to obtain the exact ratios of them [23] and the systems (including the isolation layer and the superstructure) did not yield.

\subsection{Error Calculation}

2.6.1. Calculation Accuracy. Although the accuracy of dynamic response calculation is usually expressed by the error between calculated and measured peak displacement, acceleration, or velocity in the tests, it is not rigorous to evaluate numerical simulation only based on peak data, since dynamic responses of the system are continuous process and phase is also very important. To obtain an accurate analysis result, the calculation accuracies are derived by the data near the peaks. The amount of data depends on the response of the systems. As shown in Figure 3, the data in the red box are used for accuracy analysis, e.g., $\pm 0.001 \mathrm{~m}$ is the red frame range because of the large response isolation displacements of case 211 and $\pm 0.0005 \mathrm{~m}$ is the range because of the small response of 212 . 


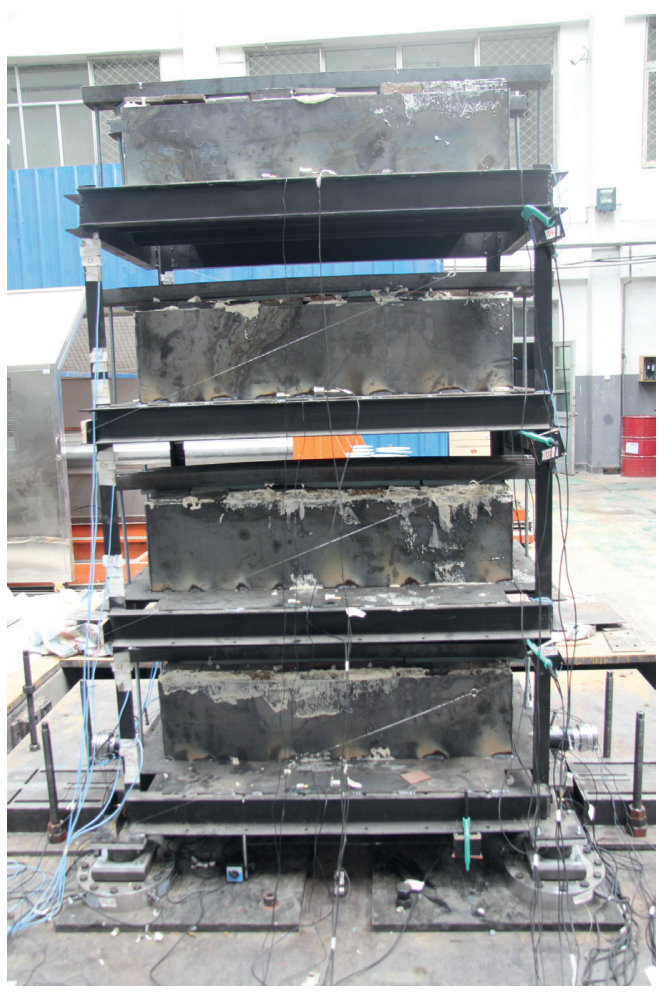

(a)

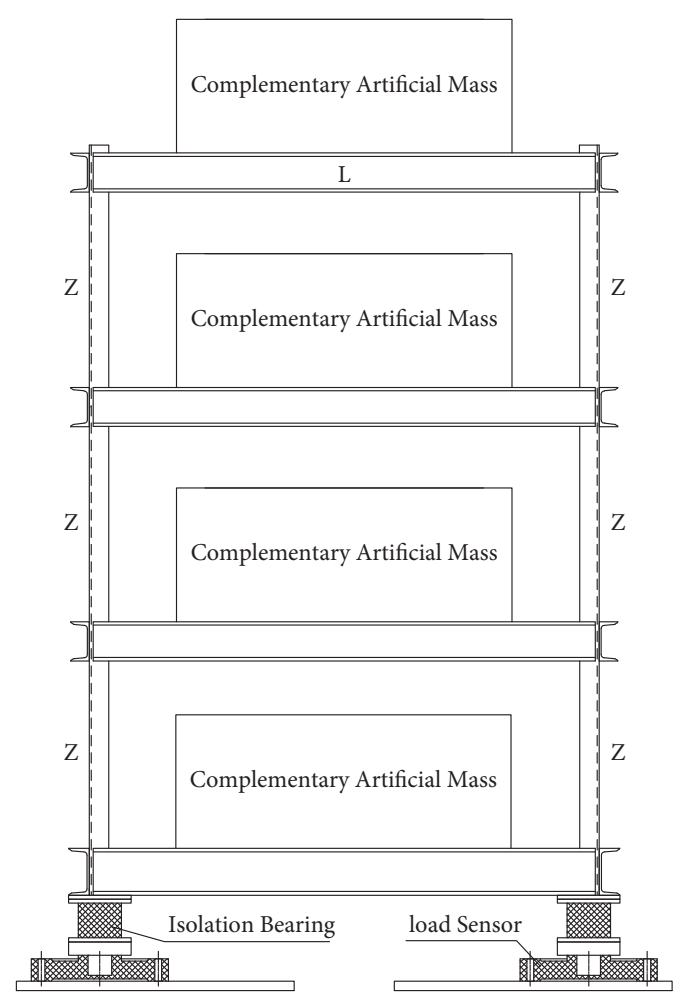

(b)

FIGURE 1: Experimental model: (a) picture and (b) sketch.

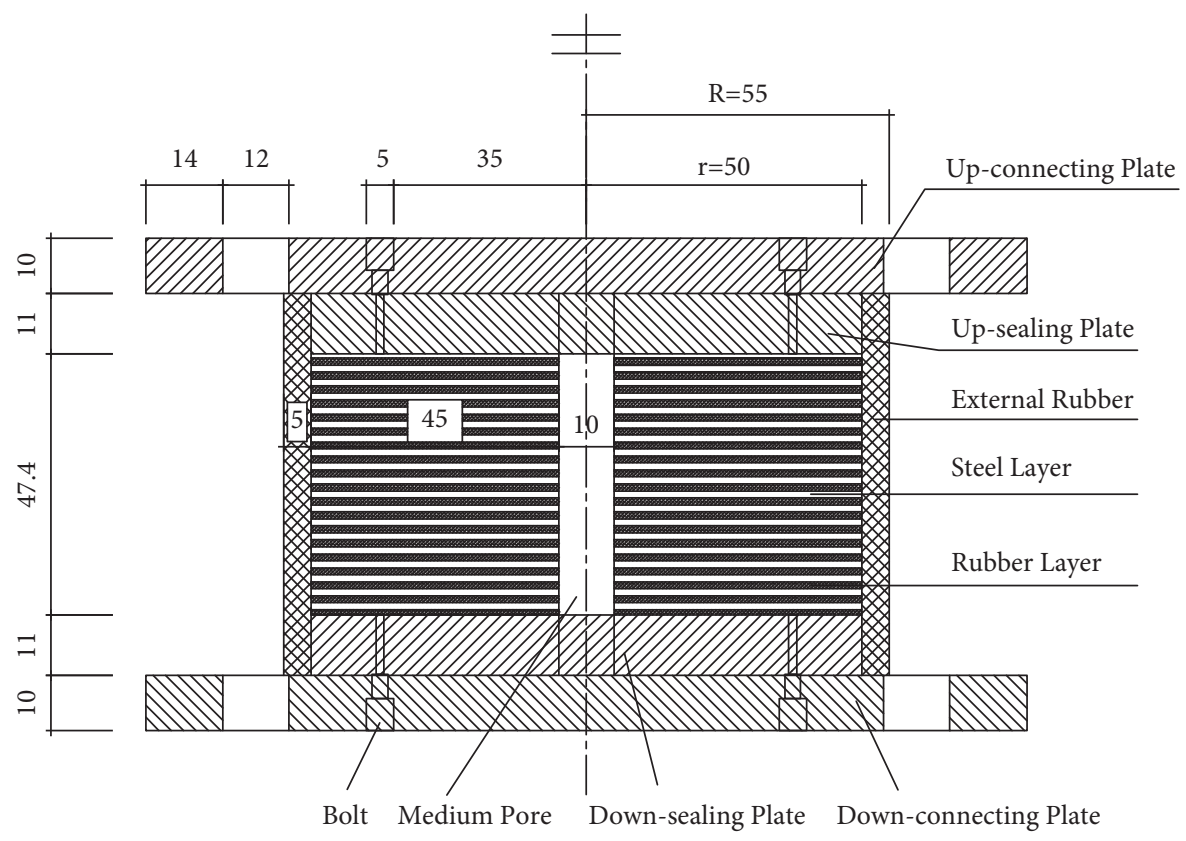

FIGURE 2: Sketch of isolation bearing.

TABLE 1: Parameters of isolation bearing.

\begin{tabular}{lccccc}
\hline Height $(\mathrm{mm})$ & $\begin{array}{c}\text { Diameter of steel layer } \\
(\mathrm{mm})\end{array}$ & $\begin{array}{c}\text { Diameter of the medium } \\
\text { pore }(\mathrm{mm})\end{array}$ & $\begin{array}{c}\text { Thickness of rubber layer } \\
(\mathrm{mm})\end{array}$ & $\begin{array}{c}\text { Thickness of steel layer } \\
(\mathrm{mm})\end{array}$ & $\begin{array}{c}\text { Shear modulus } \\
(\mathrm{G} / \mathrm{MPa})\end{array}$ \\
\hline 89.4 & 100 & 10 & $1.5 \times 18$ & $1.2 \times 17$ & 0.4 \\
\hline
\end{tabular}


TABLe 2: Ground motion.

\begin{tabular}{|c|c|c|c|c|c|c|}
\hline Name & Abbreviation & Time & Location & Duration (s) & Amplitude (gal) & Direction \\
\hline Emc-fairview & EMC00 & 1987 & Whittier Narrows & 28.26 & 130.4 & N-S \\
\hline Lwd-del amoblvd & LWD90 & 1994 & Northridge & 35.40 & 119.1 & E-W \\
\hline Pel_hollywood & PEL180 & 1971 & San Fernando & 79.48 & 167.3 & N-S \\
\hline Taft-se & TAFTSE & 1952 & California & 54.38 & 175.9 & S-E \\
\hline Tar_tarzana_90_nor & TAR90 & 1994 & Northridge & 60.00 & 174.5 & S-E \\
\hline El Centro & ELNS & 1940 & Imperial Valley & 30.00 & 341.7 & $\mathrm{~N}-\mathrm{S}$ \\
\hline
\end{tabular}

TABle 3: Test schedule.

\begin{tabular}{lccc}
\hline Serial number & Name & Ground motion & PGA $(\mathrm{g})$ \\
\hline 1 & 207 & ELNS & 0.07 \\
2 & 208 & EMC00 & 0.07 \\
3 & 209 & LWD90 & 0.07 \\
4 & 210 & PEL180 & 0.07 \\
5 & 211 & TAFTSE & 0.07 \\
6 & 212 & TAR90 & 0.07 \\
7 & 221 & ELNS & 0.20 \\
8 & 222 & EMC00 & 0.20 \\
9 & 223 & LWD90 & 0.20 \\
10 & 224 & PEL180 & 0.20 \\
11 & 225 & TAFTSE & 0.20 \\
12 & 226 & TAR90 & 0.20 \\
\hline
\end{tabular}

TABLe 4: Frequency of the experimental system.

\begin{tabular}{ccccccc}
\hline & & Nonisolated & & \multicolumn{2}{c}{ Isolated } \\
& Measured $(\mathrm{Hz})$ & Theoretical $(\mathrm{Hz})$ & Error $(\%)$ & Measured $(\mathrm{Hz})$ & Theoretical $(\mathrm{Hz})$ & Error $(\%)$ \\
\hline 1 & 3.91 & 4.35 & 11.40 & 1.74 & 7.66 & 7.83 \\
2 & 11.69 & 12.20 & 4.32 & 7.05 & 13.94 & 1.02 \\
3 & 18.20 & 17.63 & -3.13 & 13.74 & 1.45 \\
4 & $/$ & $/$ & $/$ & 18.93 & -4.47 \\
\hline
\end{tabular}

${ }^{*}$ Error $=($ theoretical - measured $) /$ measured.

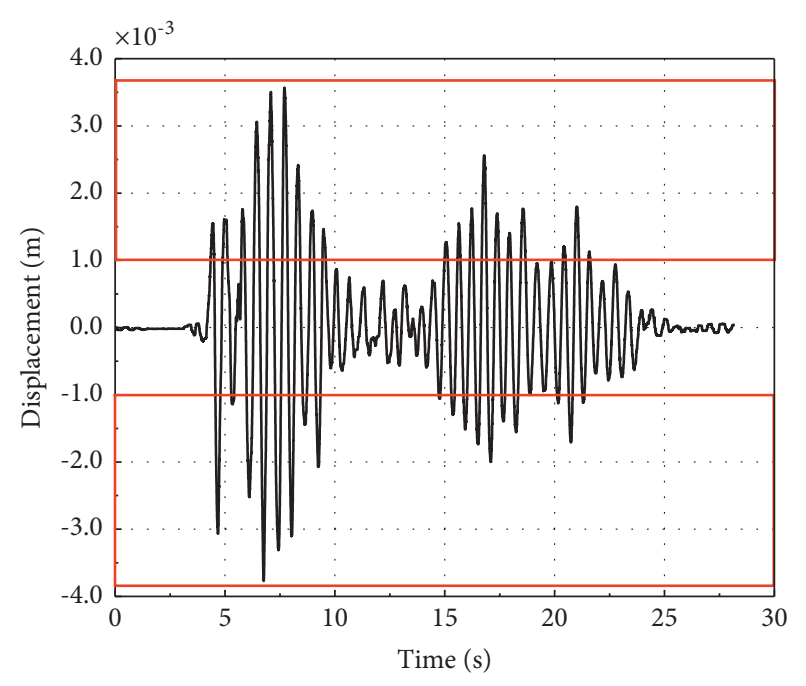

(a)

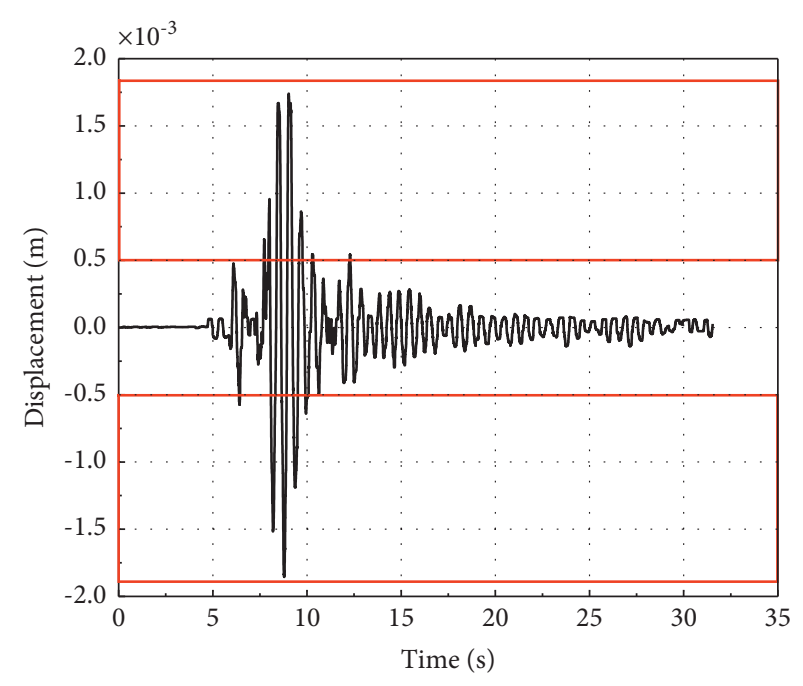

(b)

FIGURE 3: Displacement of the isolation layer (PGA =0.07 g). Isolation displacement of (a) case 211 and (b) case 212. 
2.6.2. Error Calculating Method. To ensure the accuracy of the analysis, two methods are used to calculate the errors, which are represented as $E_{1}$ and $E_{2}$.

(1) Based on Euclidean norm,

$$
E_{1}=\frac{F-F_{2}^{\prime}}{F_{2}} \times 100 \%,
$$

where $F^{\prime}$ is the data of the numerical simulation time-history curves, $F$ is the data of the measured time-history curves in the tests, and $F_{2}$ and $F-F_{2}^{\prime}$ are Euclidean norms of $F$ and $\left(F-F^{\prime}\right)$ [27].

(2) Based on the 1-norm,

$$
E_{2}=\frac{F-F_{1}^{\prime}}{F_{1}} \times 100 \%,
$$

where $F_{1}$ and $F-F_{1}^{\prime}$ are 1-norms of $F$ and $\left(F-F^{\prime}\right)$.

2.7. Damping Model. The damping force of viscous damping is proportional to the vibration velocity of the particle, as shown in equation (3). Rayleigh damping and Caughey damping are the common viscous damping models for the multi-degree-of-freedom system [27].

$$
\left[F_{c}\right]=[C] \times[\dot{X}],
$$

where $\left[F_{c}\right]$ is the viscous damping force, $[C]$ is the damping matrix, and $[\dot{X}]$ is the relative velocity of the structure.

2.7.1. Rayleigh Damping $(R D)$. The Rayleigh damping is equivalently expressed by stiffness matrix and mass matrix, and the equation is as follows [7]:

$$
[C]=a[M]+b[K] \text {, }
$$

where $[M]$ is the mass matrix and $[K]$ is the stiffness matrix. According to the strain gauge data, the superstructure has not entered plasticity, so the stiffness of the superstructure is constant. The mass coefficient $a$ and stiffness coefficient $b$ can be calculated as follows:

$$
\begin{aligned}
& a=2 \frac{\left(\xi_{i} / \omega_{i}\right)-\left(\xi_{j} / \omega_{j}\right)}{\left(1 / \omega_{i}^{2}\right)-\left(1 / \omega_{j}^{2}\right)}, \\
& b=2 \frac{\xi_{i} \omega_{j}-\xi_{j} \omega_{i}}{\omega_{j}^{2}-\omega_{i}^{2}},
\end{aligned}
$$

where $\omega_{i}, \omega_{j}, \xi_{i}$, and $\xi_{j}$ are the frequencies and corresponding damping ratios of the $i$ and $j$ vibration modes of the system, respectively. The damping ratio of other vibration modes can be calculated by the following equation.

$$
\xi_{n}=\frac{a}{2 \omega_{n}}+\frac{b \omega_{n}}{2}, \quad(n=1,2, \ldots, n) .
$$

2.7.2. Caughey Damping (CD). Caughey damping can construct a damping matrix with multiple frequencies and corresponding damping ratios, and the equation is as follows:

$$
[C]=[M] \sum_{i=1}^{n} \gamma_{i}\left([M]^{-1}[K]\right)^{i-1},
$$

where $i$ is the number of frequencies and $\gamma_{i}$ is the proportionality coefficient, and the equation is as follows:

$$
\gamma=2 Q^{-1} \xi,
$$

where $\gamma=\left(\gamma_{1}, \gamma_{2} \ldots \gamma_{n}\right)^{T} ; \quad \xi=\left(\xi_{1}, \xi_{2} \ldots \xi_{n}\right)^{T}$, in which $\xi_{1}, \xi_{2} \ldots \xi_{n}$ are the damping ratio of each vibration mode; and $Q=\left[\begin{array}{cccc}\omega_{1}^{-1} & \omega_{1}^{1} & \cdots & \omega_{1}^{2 n-3} \\ \omega_{2}^{-1} & \omega_{2}^{1} & \cdots & \omega_{2}^{2 n-3} \\ \vdots & \vdots & \cdots & \vdots \\ \omega_{n}^{-1} & \omega_{n}^{1} & \cdots & \omega_{n}^{2 n-3}\end{array}\right]$, in which $\omega_{1}, \omega_{2} \ldots \omega_{n}$ are the frequency of each vibration mode.

\subsubsection{Nonproportional Damping}

(1) Nonproportional damping based on Rayleigh damping (NP-RD):

Because there is big difference of properties between the isolation layer and the superstructure, NP$\mathrm{RD}$ is also used to represent the damping of the isolated structure $[10,30,36,39]$. The equation is as follows:

$$
\left[C_{R}\right]=\left[\begin{array}{cc}
c_{b}+c_{1} & -c^{T} \\
-c & {\left[C_{s}\right]}
\end{array}\right],
$$

where $\left[C_{s}\right]$ is the damping matrix of the superstructure and is calculated according to equation (4); $[M]$ and $[K]$ should be the mass matrix and stiffness matrix of the superstructure, respectively. The mass coefficient $a$ and stiffness coefficient $b$ are calculated by the frequency and damping ratio of the nonisolated structure; $c_{1}$ is the damping of the first story of the superstructure, and $c_{b}$ is the damping of the isolation layer and is calculated by

$$
c_{b}=2 m_{b} \omega_{b} \xi_{b},
$$

where $m_{b}$ is the total mass of the superstructure, $\omega_{b}$ is the fundamental vibration frequency of the isolated structure, and $\xi_{b}$ is the damping ratio of the isolated structure.

(2) Nonproportional damping based on Caughey damping (NP-CD):

The calculation formulas of NP-RD and NP-CD are identical, as shown in (9), where $\left[C_{s}\right]$ is calculated according to (7); $[M]$ and $[K]$ are also the mass matrix and stiffness matrix of the superstructure, respectively; and the proportional coefficient $\gamma_{n}$ is calculated by (8).

\section{Effect of Frequency}

$\mathrm{CD}$ and NP-CD are constructed by the damping matrix $(n \geq 2)$ of multiple order frequencies, whereas $\mathrm{RD}$ and 
NP-RD are constructed by the damping matrix of only two of them. It is meaningful to research which two frequencies are the most reasonable for the calculation of RD and NP-RD.

\subsection{Frequency Selection for Rayleigh Damping (RD)}

3.1.1. For $P G A=0.07 \mathrm{~g}$. Only the isolation displacement responses are analyzed in this section as few deformations were recorded in the superstructure. The damping matrixes are calculated by (4) with the 1st modal damping ratio and frequencies of 1 st and 2 nd modal (1\&2), 1st and 3rd modal (1\&3), 1 st and 4 th modal (1\&4), 2nd and 3rd modal (2\&3), 2nd and 4th modal (2\&4), and 3nd and 4th modal (3\&4), respectively. All the damping matrixes are used for dynamic numerical calculation to simulate the tests subjected to a PGA of $0.07 \mathrm{~g}$, as shown in Table 5. "Frequency pair" indicates the two frequencies used to construct damping matrix. E1 and E2 are errors obtained by the above error calculation methods.

The errors of test and the calculations with damping matrix calculated by different frequency pairs are shown in Figure 4. Comparisons of the calculated and experimental time-history curves of isolation displacements are shown in Figure 5. The figures denote that calculations with the damping of $1 \& 2,1 \& 3$, and $1 \& 4$ modal frequencies are more consistent with the experimental results. The damping derived from the highest two frequencies $(3 \& 4)$ results in the largest calculation error. Although the errors with frequency pairs $1 \& 2,1 \& 3$, and $1 \& 4$ are similar, frequency pair $1 \& 4$ led to the smallest error. So, the first and highest frequencies are recommended to be selected in the construction of $\mathrm{RD}$.

3.1.2. For $P G A=0.2 \mathrm{~g}$. Calculations were conducted under $\mathrm{PGA}=0.2 \mathrm{~g}$, as shown in Table 6. The displacements of both the isolated base and the superstructure are recorded exactly in the intensity, so the contrast of the displacement of the superstructure is plotted in this section.

(1) Displacement of the Isolation Layer. The errors for all the cases based on different frequency pairs are shown in Figure 6.

The figures show that the damping based on the $1 \& 2$, $1 \& 3$, and $1 \& 4$ modal frequencies led to smallest errors. The damping based on the modal frequencies of $2 \& 3,2 \& 4$, and $3 \& 4$ results in larger calculation errors, and the error base on $3 \& 4$ frequencies is the largest. Frequency pair $1 \& 4$ can cause the least error and is preferred for structural calculation.

(2) Displacement of the First Story. The errors for each case based on different frequency pairs are shown in Figure 7. Comparisons of the calculated and experimental curves of the displacement time histories of the first story are shown in Figure 8.

As can be seen from figures, the damping based on the $1 \& 2,1 \& 3$, and $1 \& 4$ modal frequencies' constructions can generate the calculations more consistent with the tests. The other frequency pairs cause larger calculation error, and frequency pair $3 \& 4$ led to the largest error.
In conclusion, all the calculation cases with the 1 st modal frequency of the system have relatively small errors, so the 1st modal frequency is firstly recommended to be utilized in $\mathrm{RD}$. In most cases, the highest modal frequency results in the least error when it pairs with the 1st modal frequency, which is also recommended to construct RD.

\subsection{Frequency Selection for Nonproportional Rayleigh Damping (NP-RD)}

3.2.1. For $P G A=0.07 \mathrm{~g}$. There are only three modal frequencies for the superstructure, i.e., nonisolated system. So, there are only three frequency pairs that can be matched for NP-RD. The test schedule is shown in Table 7.

The errors of the isolation layer for each case under different frequency pairs are shown in Figure 9. The displacement time-history curves of the isolation layer are shown in Figure 10.

It can be seen from the figures that frequency pair $2 \& 3$ led to the smallest calculation errors and the error differences from the three frequency pairs are less than $4 \%$ in all the cases, which denotes that the frequency selection of superstructure has little influence on the numerical analysis.

3.2.2. For $P G A=0.2 \mathrm{~g}$. The calculations, as shown in Table 8, were performed when system is subjected to $P G A=0.2 \mathrm{~g}$.

(1) Displacement of the Isolation Layer. The isolation displacement errors for cases with different frequency pairs are shown in Figure 11. It can be seen from the figures that the error differences between the frequency pairs are similar to the differences under $\mathrm{PGA}=0.07 \mathrm{~g}$.

(2) Displacement of the First Story. The first story displacement errors for cases under different frequency pairs are shown in Figure 12. It can be seen from the figures that the error difference results are similar to the results on isolation displacements.

\section{Effect of the Damping Model Selection}

4.1. Effect on the Displacement of the Isolation Layer. In this section, the effects of numerical calculations using damping models of RD, NP-RD, CD, and NP-CD on the displacements of the isolation layer are analyzed. Herein, RD is calculated using the $1 \& 4$ frequencies of the isolated structure, and NP-RD is calculated using the $2 \& 3$ frequencies of the nonisolated structure according to the conclusion of Section 3. CD is calculated using the $1-4$ frequencies of isolated structure, and NP-CD is calculated using the 1-3 frequencies of the nonisolated system.

4.1.1. For $P G A=0.07 \mathrm{~g}$. The test schedule is shown in Table 9 , and the errors of isolation displacements for all cases calculated using different damping models are shown in Figure 13. From the figures, it can be seen that $\mathrm{RD}$ using the $1 \& 4$ frequencies of the isolated structure results in the smallest calculation errors and NP-CD using the 1-3 
TABLE 5: Calculation schedule of PGA $=0.07 \mathrm{~g}$.

\begin{tabular}{lcc}
\hline Experimental case & Ground motion & Frequency pair \\
\hline 207 & ELNS & \\
208 & EMC00 & \\
209 & LWD90 & $1 \& 2 ; 1 \& 3 ; 1 \& 4 ; 2 \& 3 ; 2 \& 4 ; 3 \& 4$. \\
210 & PEL180 & \\
211 & TAFTSE & \\
212 & TAR90 & \\
\hline
\end{tabular}

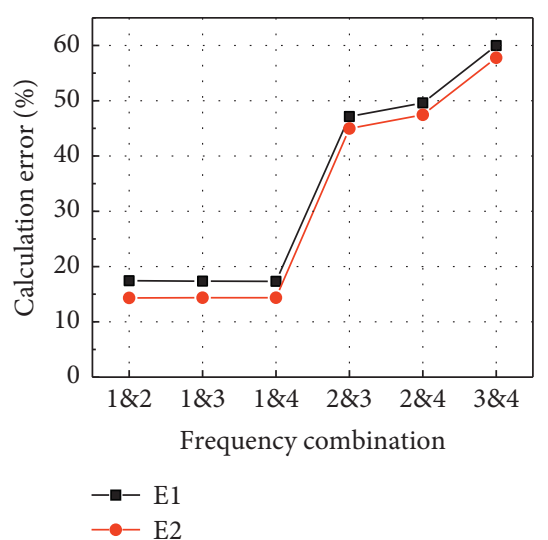

(a)

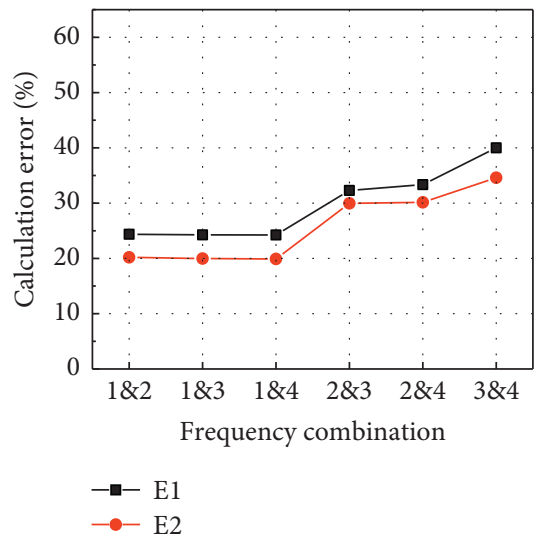

(d)

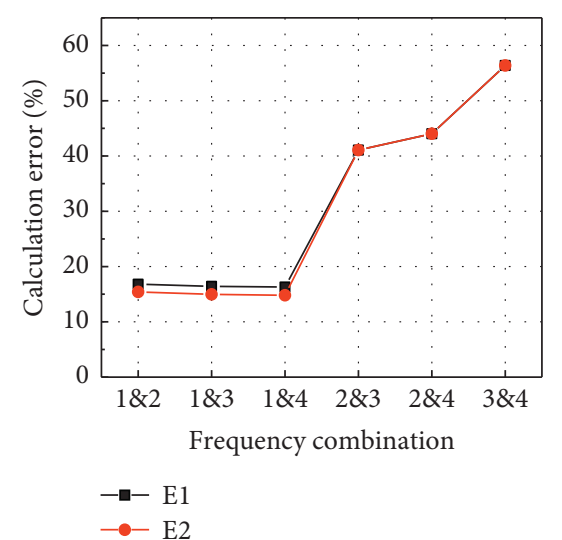

(b)

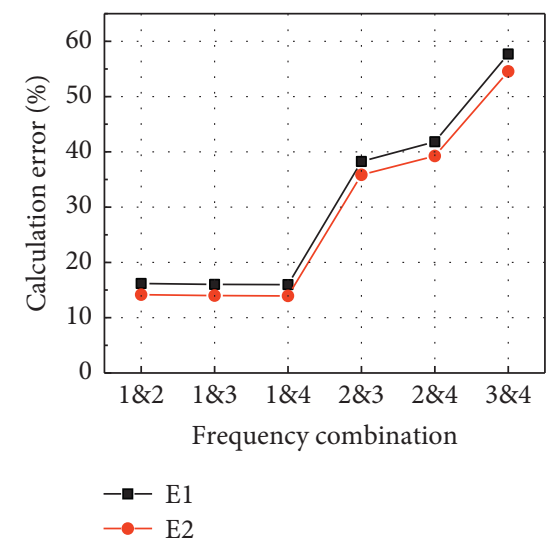

(e)

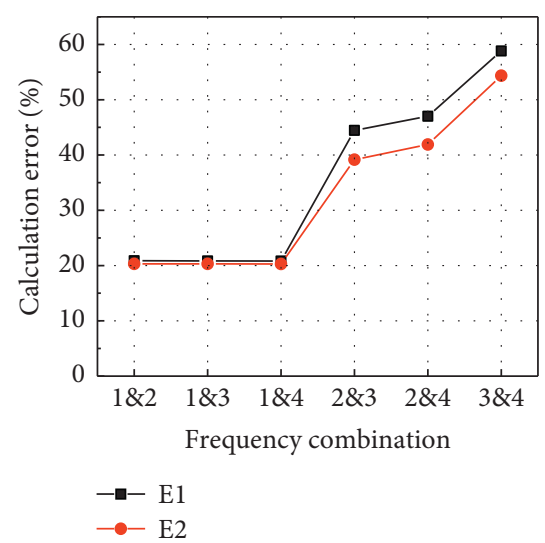

(c)

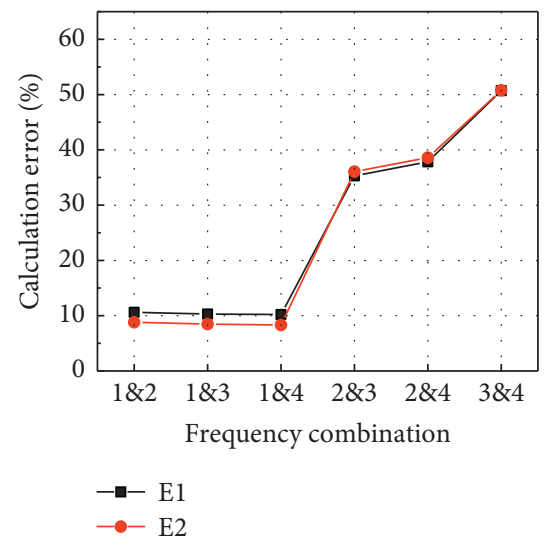

(f)

Figure 4: Calculation error of isolation displacement by using RD (PGA=0.07 g): (a) case 207, (b) case 208, (c) case 209, (d) case 210, (e) case 211 , and (f) case 212.

frequencies of the nonisolated structure contributes to the second smallest calculation errors, which are close to the effects of $\mathrm{RD}$. CD using the 1-4 frequencies of the isolated structure has the largest calculation errors.

4.1.2. For $P G A=0.2 \mathrm{~g}$. The test schedule is shown in Table 10 , and the isolation displacement errors for all cases calculated using different damping models are shown in Figure 14. From the figures, it can be seen that except for a slight difference in the error E1 of case 225, the conclusion obtained from the other data is as same as the conclusion of PGA $=0.07 \mathrm{~g}$, i.e., the calculation error of $\mathrm{RD}$ using the $1 \& 4$ frequencies of the isolated structure and NP-CD using the 1-3 frequencies of the nonisolated structure led to the least errors.
4.2. Effect on the Displacement of the First Story. According to the conclusions of Section 3, all frequency pairs including the 1st modal frequency generate desirable results on calculation errors. Therefore, frequency pairs $1 \& 2,1 \& 3$, and $1 \& 4$ are all utilized to construct $\mathrm{RD}$ in this section. The test schedule is shown in Table 11.

The errors of the first story displacement between the tests and calculations under different damping models are shown in Figure 15. Figures 16 and 17 show the comparison of the displacement time histories of the first story under cases 221 and 225 (cases with the maximum structural responses). In the figures, the damping models are $\mathrm{RD}$ with $1 \& 4$ frequencies of the isolated structure, $\mathrm{RD}$ with $1 \& 2$ frequencies of the isolated structure, and NP-CD with 1-3 frequencies of the nonisolated structure. From the figures, it 


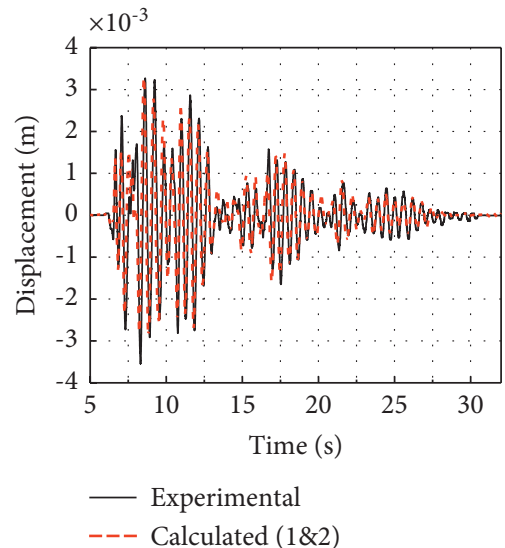

(a)

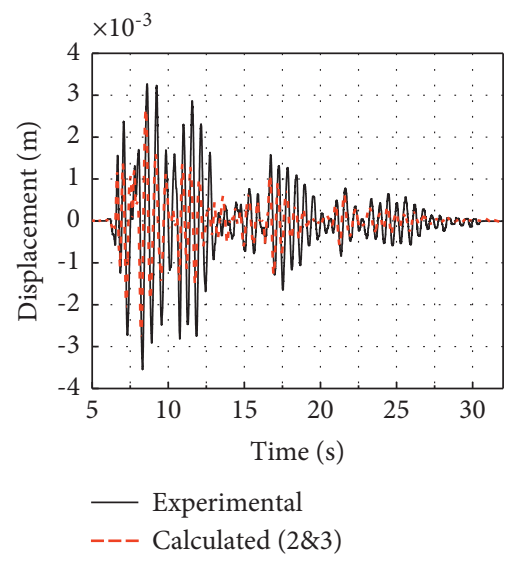

(d)

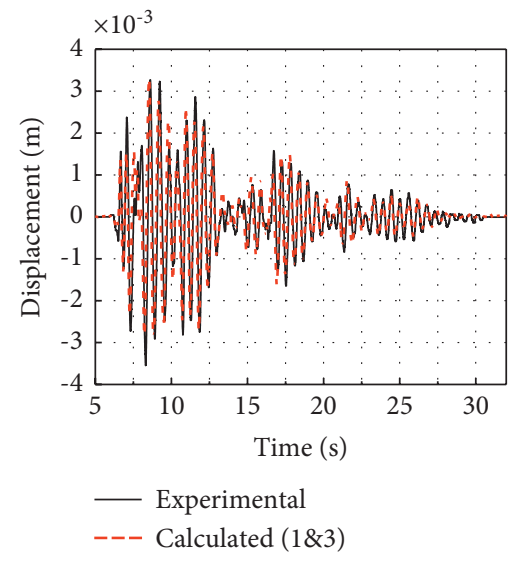

(b)

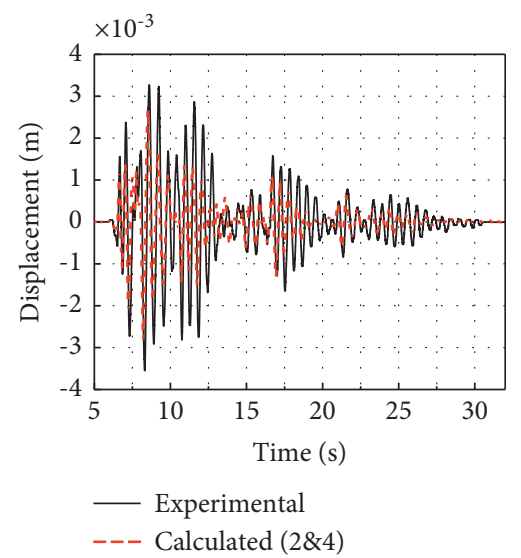

(e)

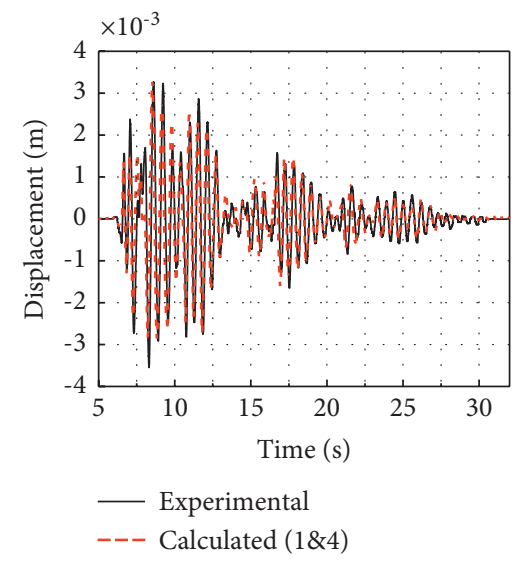

(c)

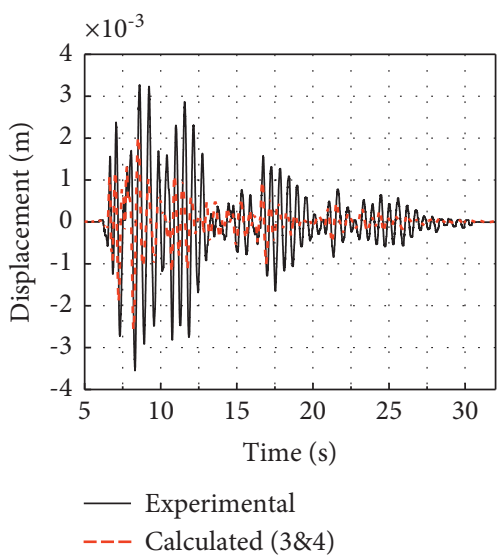

(f)

Figure 5: Comparison of calculated and experimental displacement curves of the isolation layer with RD based on frequency pairs (case 207): (a) $1 \& 2$, (b) $1 \& 3$, (c) $1 \& 4$, (d) $2 \& 3$, (e) $2 \& 4$, and (f) $3 \& 4$.

TABLE 6: Calculation schedule of PGA $=0.2 \mathrm{~g}$.

\begin{tabular}{lcc}
\hline Experimental case & Ground motion & Frequency pair \\
\hline 221 & ELNS & \\
222 & EMC00 & \\
223 & LWD90 & $1 \& 2 ; 1 \& 3 ; 1 \& 4 ; 2 \& 3 ; 2 \& 4 ; 3 \& 4$. \\
224 & PEL180 & \\
225 & TAFTSE & \\
226 & TAR90 & \\
\hline
\end{tabular}

can be seen that RD and NP-CD cause relatively small calculation errors and the errors under the two damping models are similar. CD using the 1-4 frequencies of the isolated structure generates the largest calculation error.

\section{Discussion}

For the frequency selection in RD and NP-RD, the isolation frequency is the most influential in all the frequencies for the numerical calculation of isolated structures. The first modal frequency is the representation of isolation layer frequency in the isolated system. When the first modal frequency is used in the calculation of RD, the dynamic analysis has the least error, meanwhile the other frequencies has less effect in the calculation errors. The isolation frequency is tested and used in NP-RD separately, which causes the frequency selection from the superstructure to be insignificant.

For damping model selection, the error analysis based on $\mathrm{RD}, \mathrm{CD}, \mathrm{NP}-\mathrm{RD}$, and NP-CD indicates that the calculation accuracy of RD and NP-CD is similar but significantly better than the other two damping models. According to the comparison of the displacement data of the isolation layer and the first story, the order of the calculation accuracies of the damping model is RD or NP-CD $>$ NP-RD $>$ CD.

Although only PGA of $0.07 \mathrm{~g}$ and $0.20 \mathrm{~g}$ are used in tests and calculations, the conclusions can be used for the 


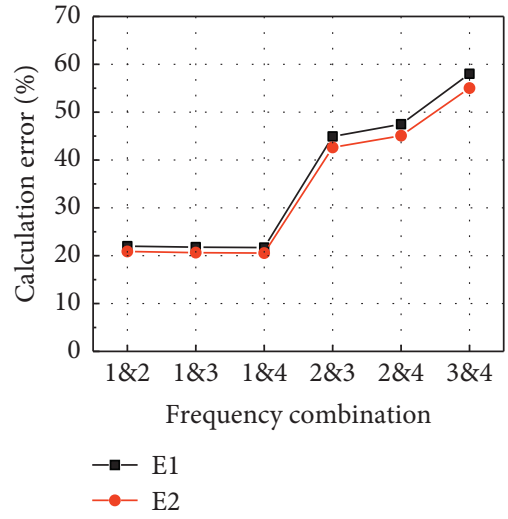

(a)

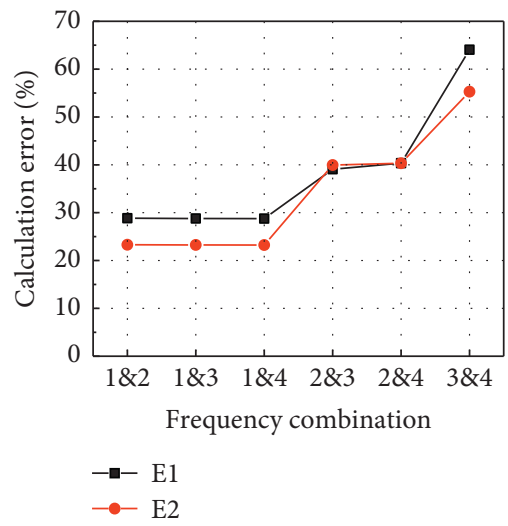

(d)

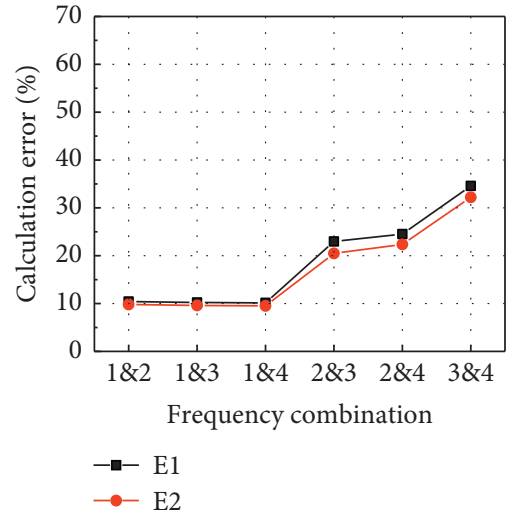

(b)

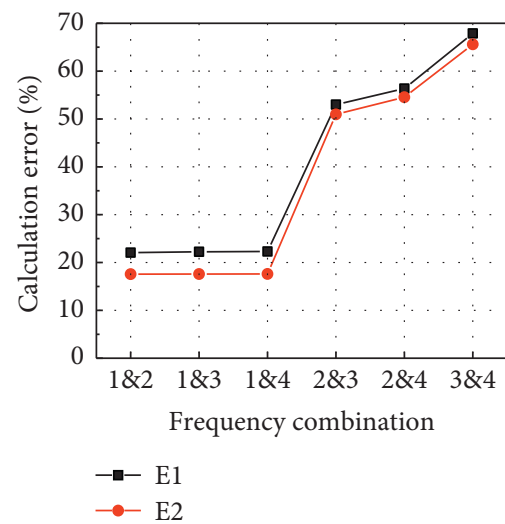

(e)

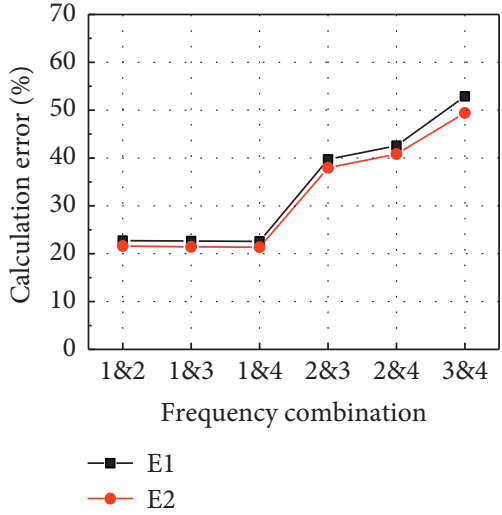

(c)

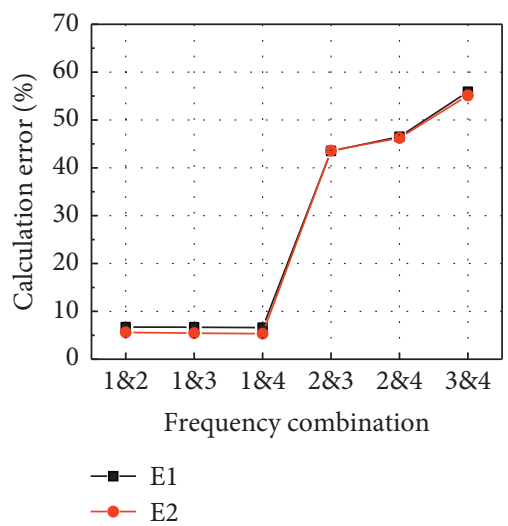

(f)

FIGURE 6: Calculation error of isolation displacement by using RD (PGA = 0.2 g): (a) case 221, (b) case 222, (c) case 223, (d) case 224, (e) case 225 , and (f) case 226.

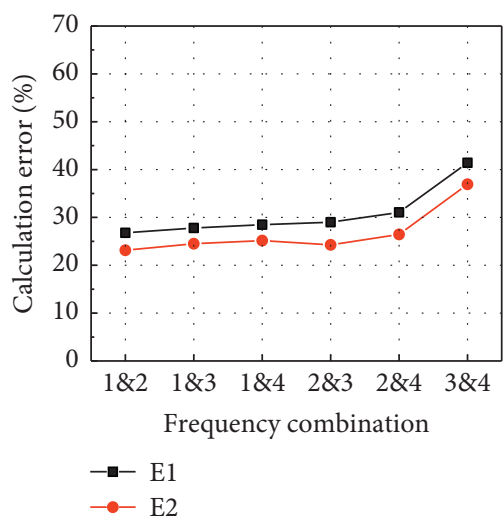

(a)

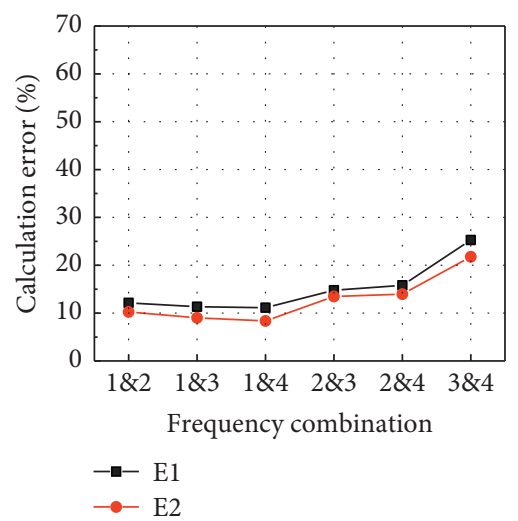

(b)

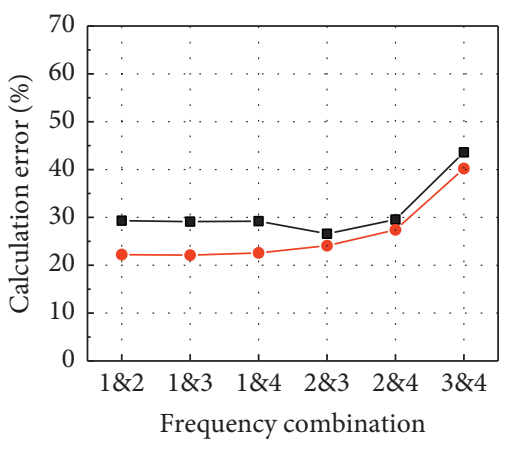

$-\mathrm{E} 1$

$\rightarrow$ E2

(c)

Figure 7: Continued. 


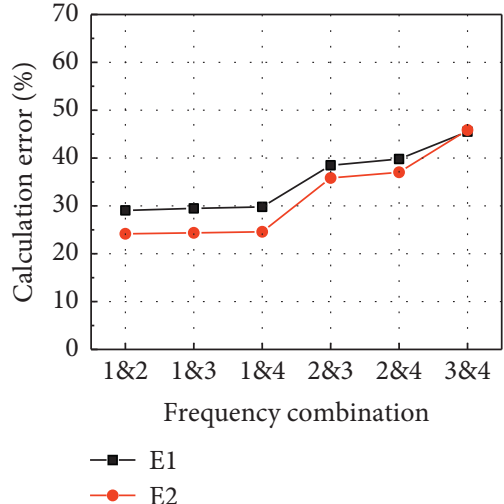

(d)

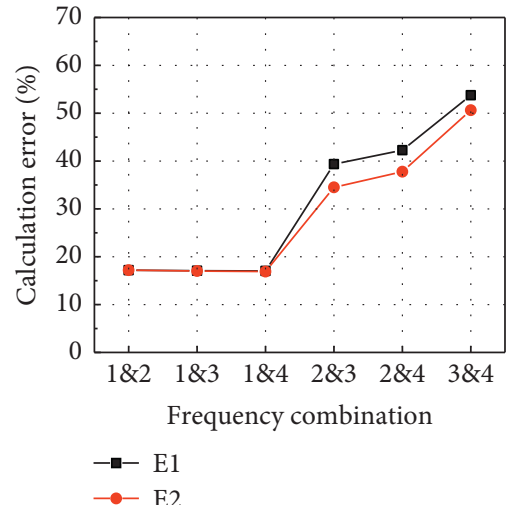

(e)

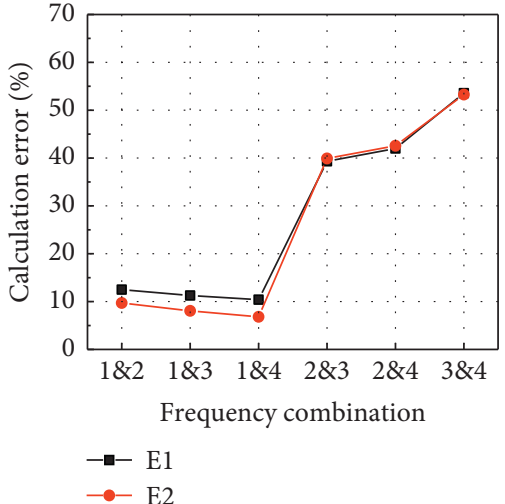

(f)

Figure 7: Calculation errors of the first story displacement by using RD (PGA=0.2 g): (a) case 221, (b) case 222, (c) case 223, (d) case 224, (e) case 225, and (f) case 226.
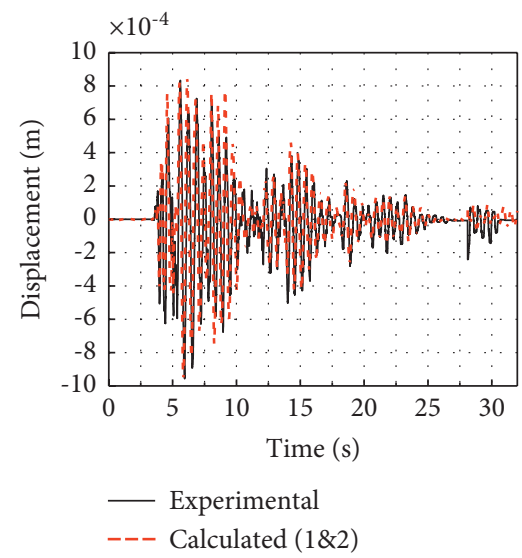

(a)
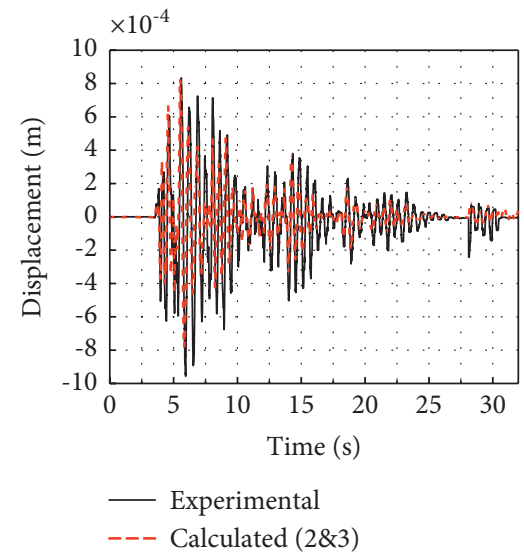

(d)
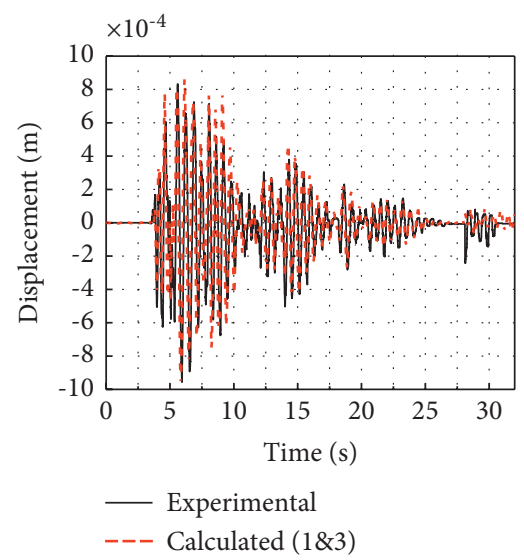

(b)

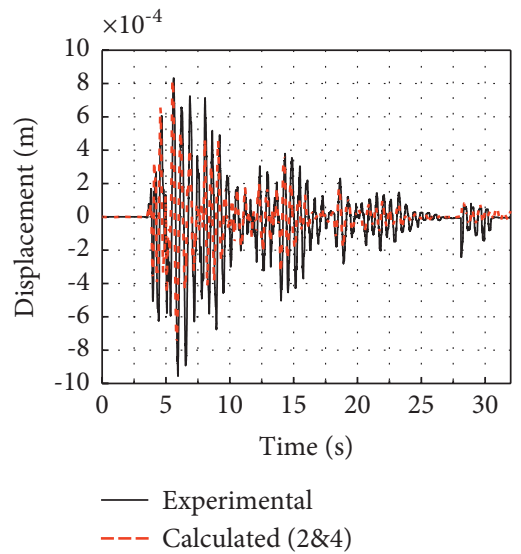

(e)

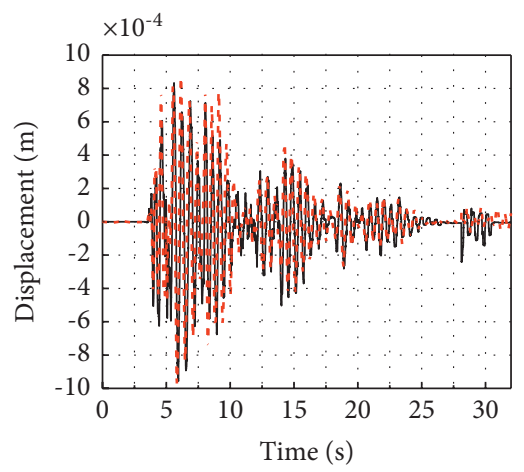

- Experimental

--- Calculated (1\&4)

(c)

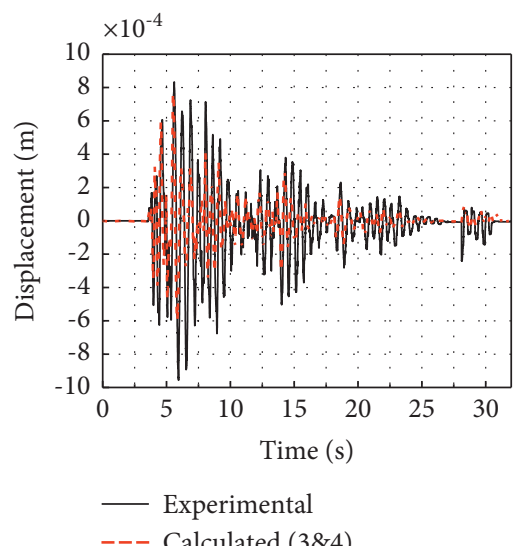

(f)

FIGURE 8: : Comparisons of calculated and experimental displacement curves of the first story with RD based on frequency pairs (case 221): (a) $1 \& 2$, (b) $1 \& 3$, (c) $1 \& 4$, (d) $2 \& 3$, (e) $2 \& 4$, and (f) $3 \& 4$.

PGA range from $0.07 \mathrm{~g}$ to $0.20 \mathrm{~g}$, since the results are similar in the two PGAs and isolation system and superstructure are elastic. However, applicability of the conclusion for PGA $>0.20 \mathrm{~g}$ is still inconclusive because the damping changes dramatically as the structure enters plasticity. 
TABLe 7: Calculation schedule with PGA $=0.07 \mathrm{~g}$.

\begin{tabular}{lccr}
\hline Experimental case & Ground motion & Frequency pair & Error \\
\hline 207 & ELNS & & \\
208 & EMC00 & $1 \& 2 ; 1 \& 3 ; 2 \& 3$ & E1, E2 \\
209 & LWD90 & & \\
210 & PEL180 & & \\
211 & TAFTSE & & \\
212 & TAR90 & & \\
\hline
\end{tabular}

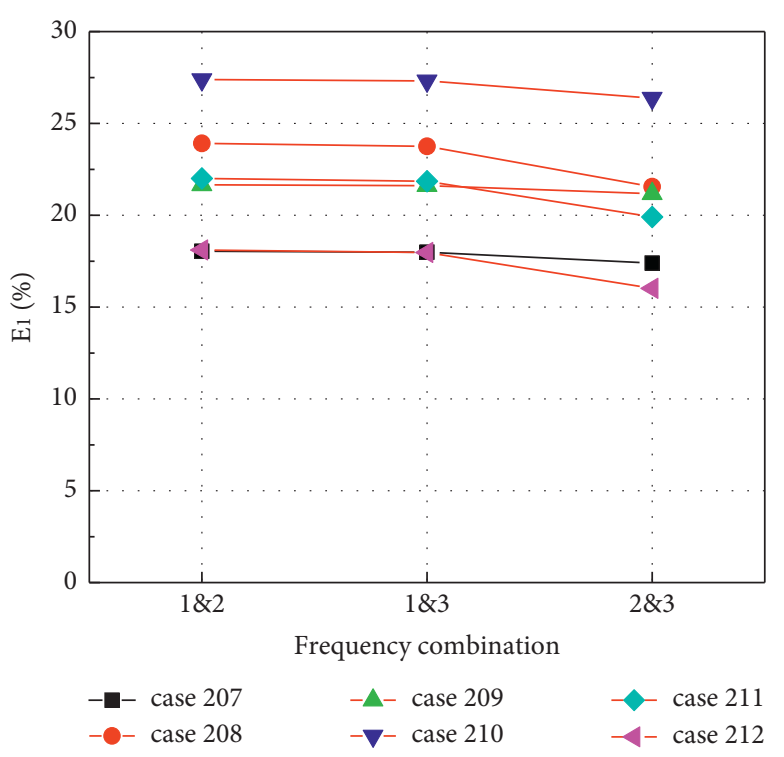

(a)

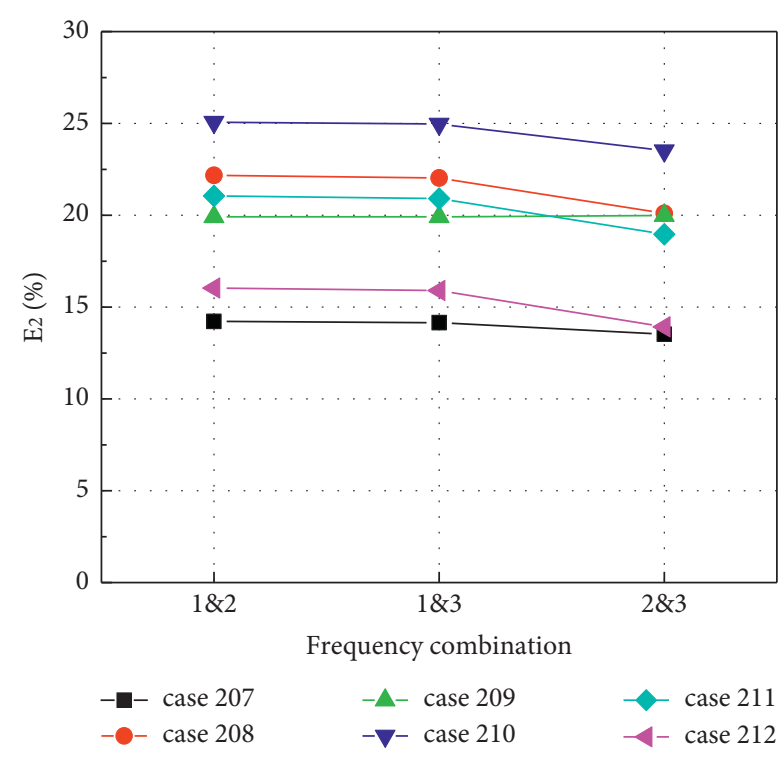

(b)

Figure 9: Calculation error of isolation layer displacement by using NP-RD (PGA=0.07 g): (a) E1 and (b) E2.

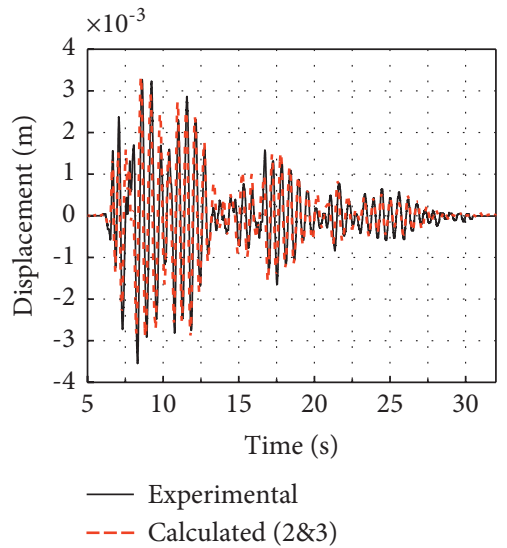

(a)
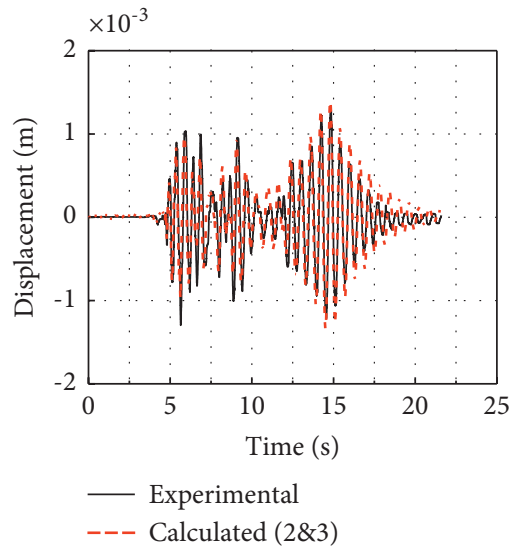

(b)

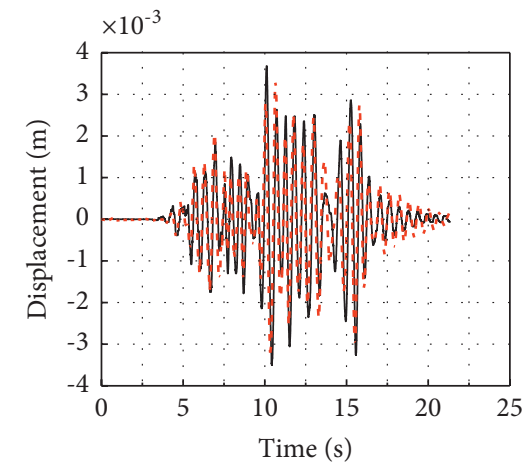

- Experimental

--- Calculated $(2 \& 3)$

(c)

FIgURe 10: Continued. 


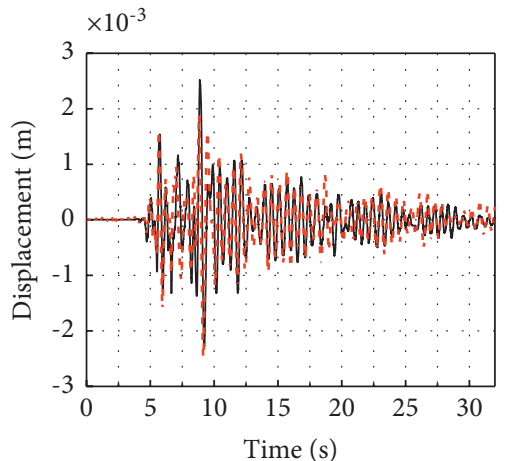

- Experimental
-- Calculated $(2 \& 3)$

(d)

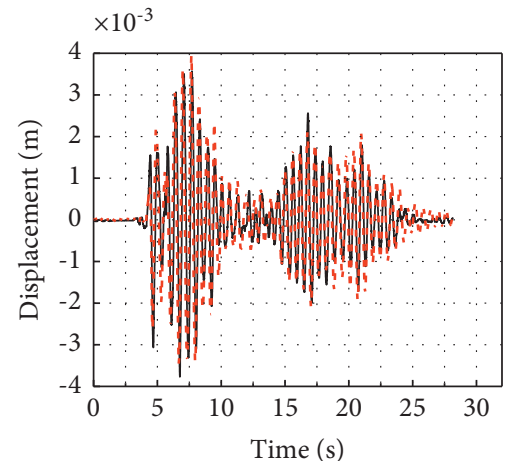

- Experimental

--- Calculated (2\&3)

(e)

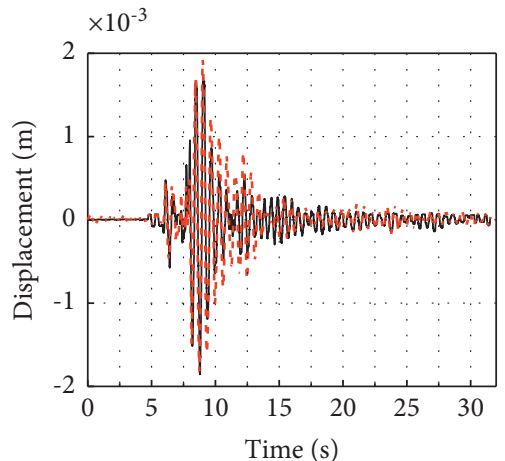

- Experimental

--- Calculated (2\&3)

(f)

FIGURE 10: Comparisons of calculated and experimental displacement curves of the isolation layer by using NP-RD (frequency pair 2\&3): (a) case 207, (b) case 208, (c) case 209, (d) case 210, (e) case 211, and (f) case 212.

TABLE 8: Calculation schedule with PGA $=0.2 \mathrm{~g}$.

\begin{tabular}{|c|c|c|c|}
\hline Experimental case & Ground motion & Frequency pair & Error \\
\hline 221 & ELNS & \multirow{6}{*}{$1 \& 2 ; 1 \& 3 ; 2 \& 3$} & \multirow{6}{*}{ E1, E2 } \\
\hline 222 & EMC00 & & \\
\hline 223 & LWD90 & & \\
\hline 224 & PEL180 & & \\
\hline 225 & TAFTSE & & \\
\hline 226 & TAR90 & & \\
\hline
\end{tabular}

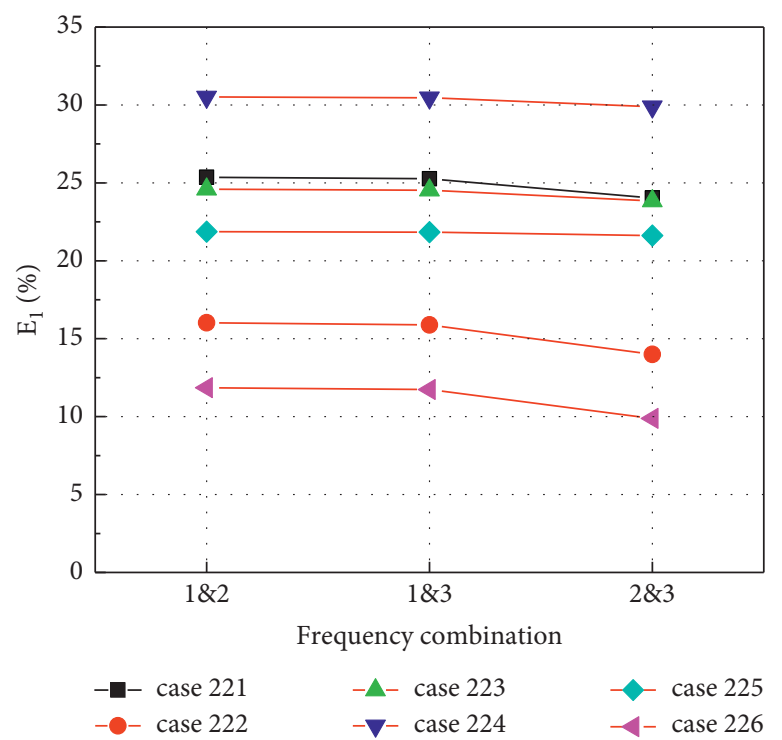

(a)

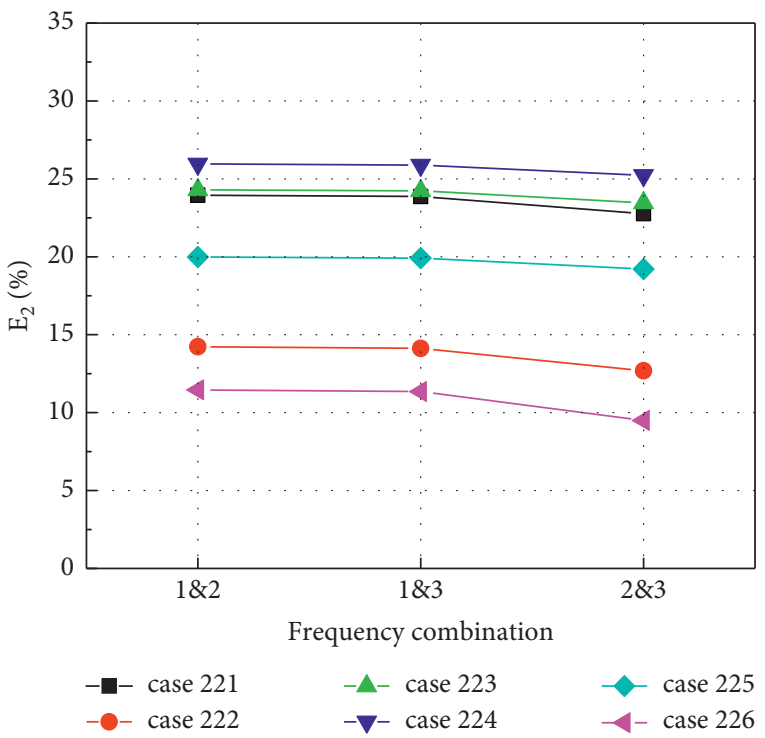

(b)

Figure 11: Calculation errors of isolation layer displacement by using NP-RD (PGA=0.2 g): (a) E1 and (b) E2. 


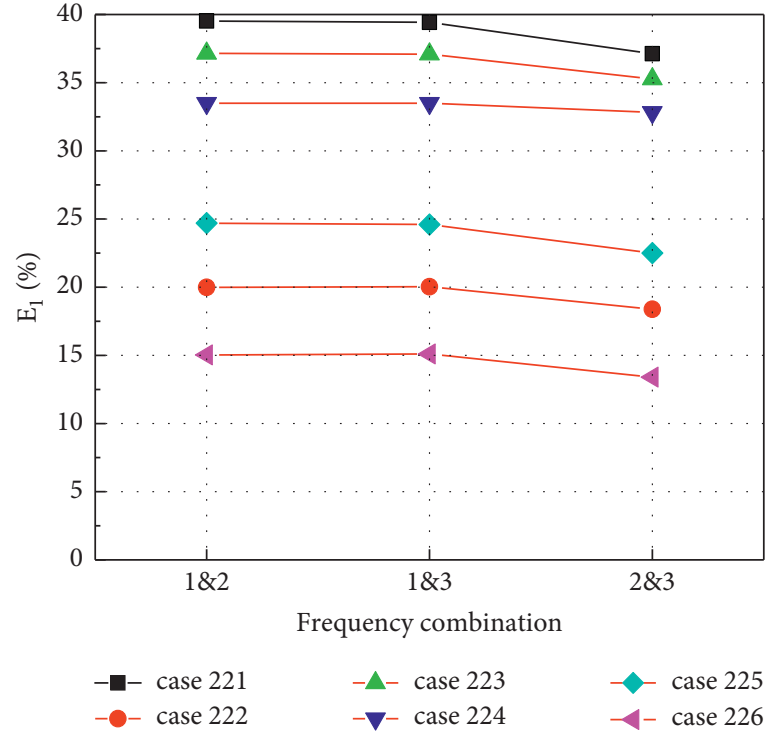

(a)

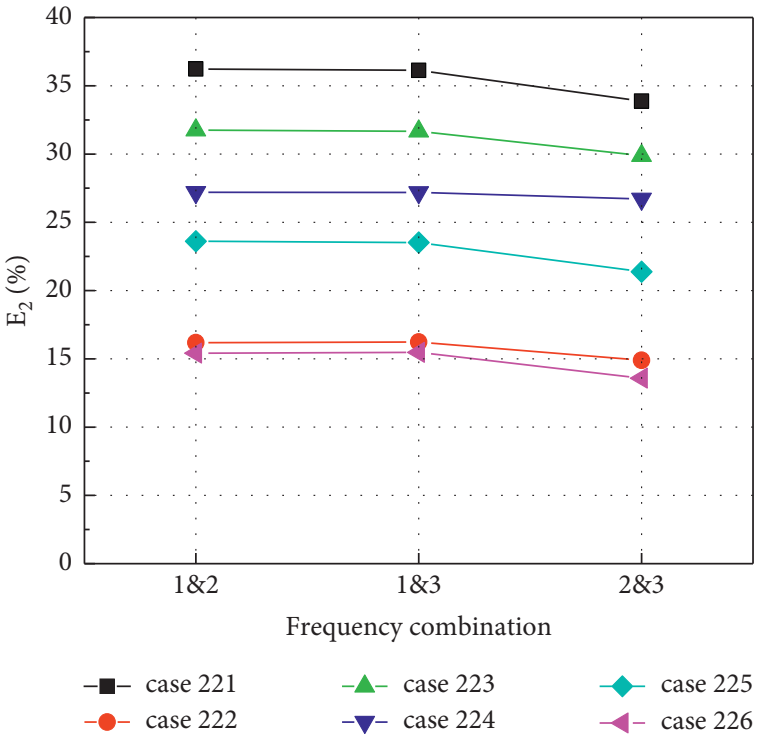

(b)

Figure 12: Calculation errors of the first story displacement by using NP-RD (PGA=0.2 g): (a) E1 and (b) E2.

Table 9: Calculation schedule with PGA $=0.07 \mathrm{~g}$.

\begin{tabular}{lcc}
\hline Damping model & \multicolumn{1}{c}{ Frequency } & Experimental case \\
\hline RD & $1 \& 4$ frequencies of the isolated system & \\
NP-RD & $2 \& 3$ frequencies of the nonisolated system & Case 207-212 \\
CD & $1-4$ frequencies of the isolated system & \\
NP-CD & $1-3$ frequencies of the nonisolated system & \\
\hline
\end{tabular}

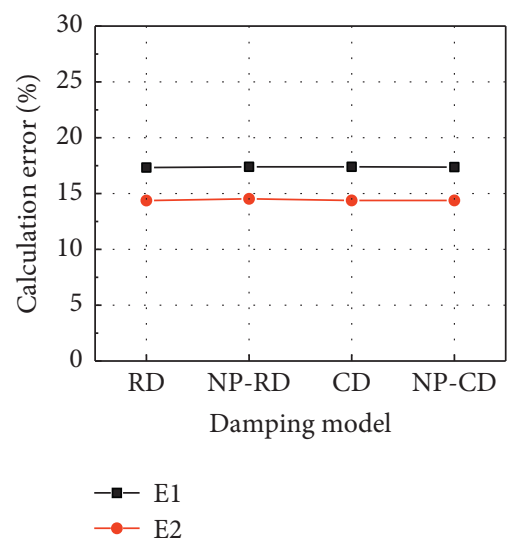

(a)

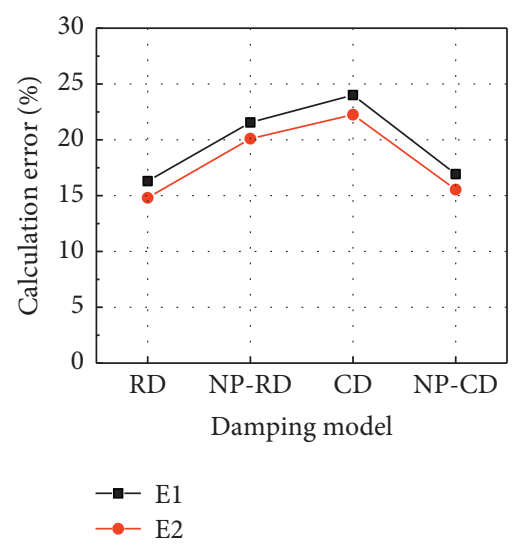

(b)

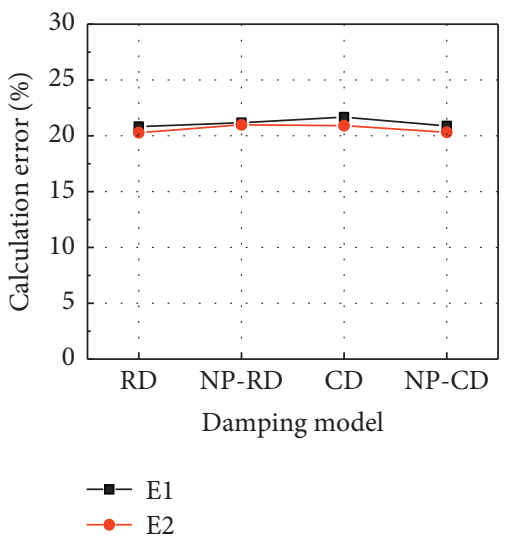

(c)

FIgUre 13: Continued. 


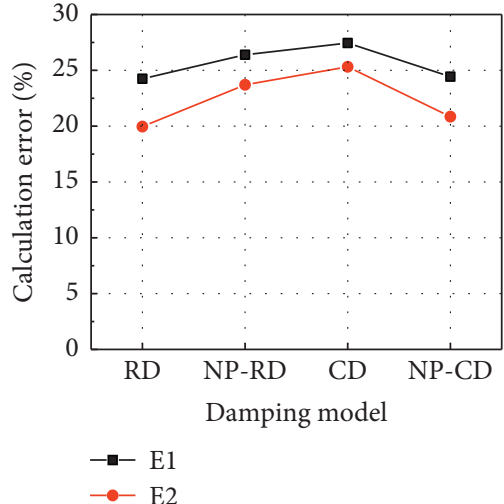

(d)

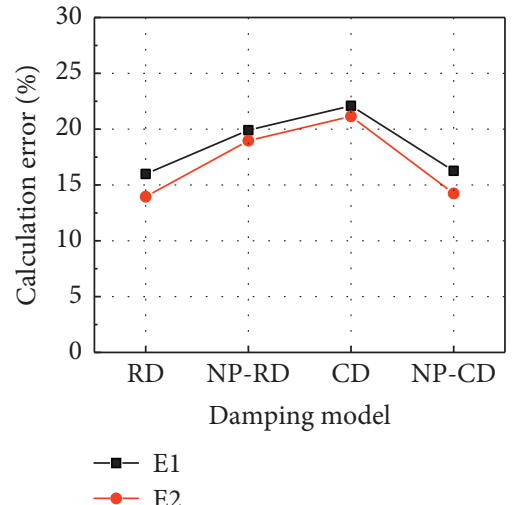

(e)

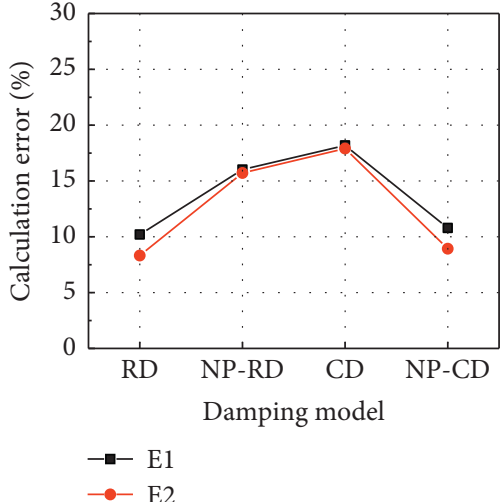

(f)

Figure 13: Calculation errors of isolation displacement by using different damping models (PGA = 0.07 g): (a) case 207, (b) case 208, (c) case 209, (d) case 210, (e) case 211, and (f) case 212.

TABLe 10: Calculation schedule with $P G A=0.2 \mathrm{~g}$.

\begin{tabular}{lcc}
\hline Damping model & Frequency & Experimental case \\
\hline RD & $1 \& 4$ frequencies of the isolated system & \\
NP-RD & $2 \& 3$ frequencies of the nonisolated system & Case 221-226 \\
CD & $1-4$ frequencies of the isolated system & \\
NP-CD & $1-3$ frequencies of the nonisolated system & \\
\hline
\end{tabular}

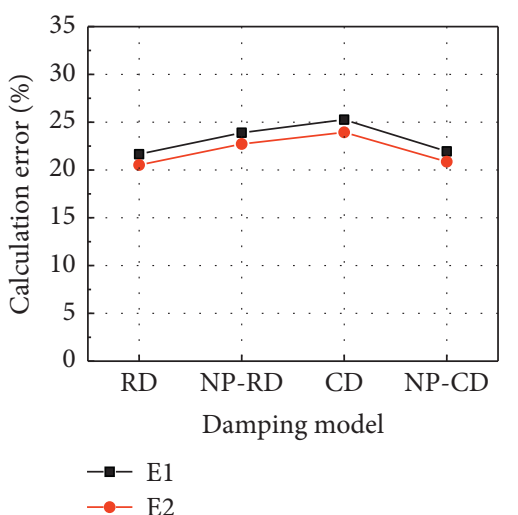

(a)

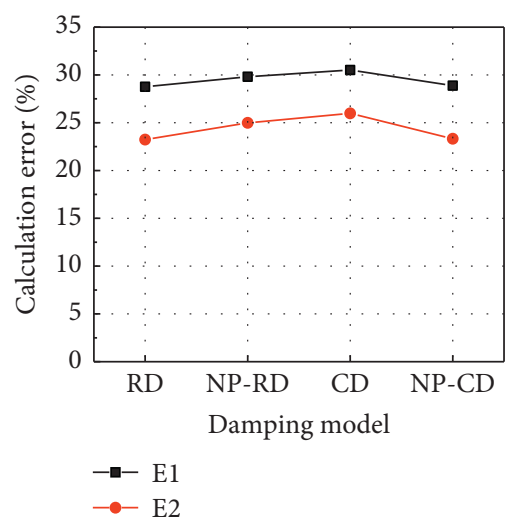

(d)

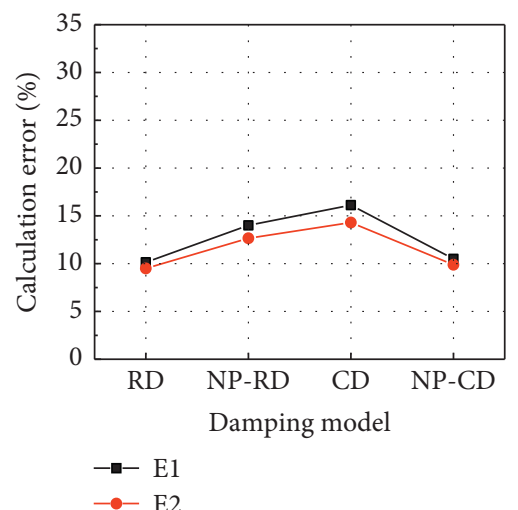

(b)

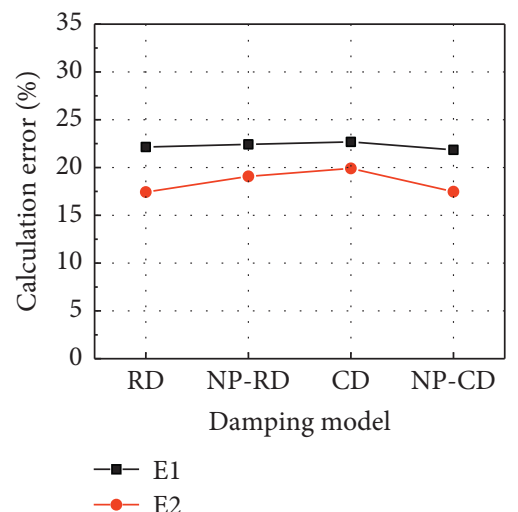

(e)

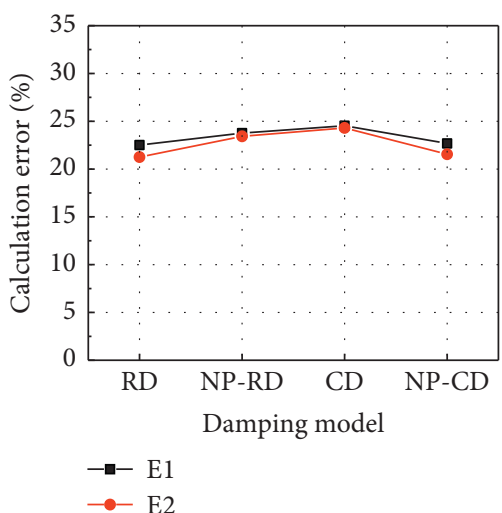

(c)

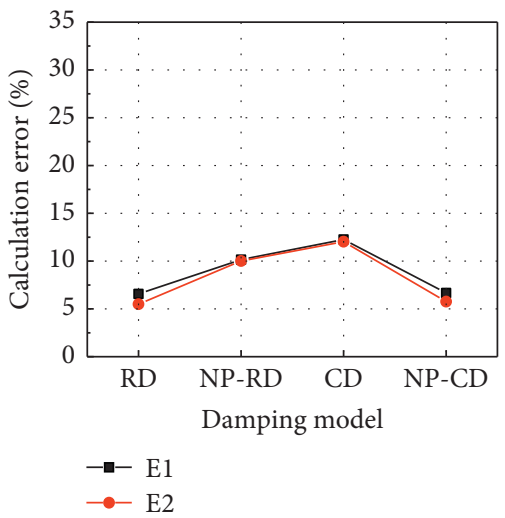

(f)

FIGURE 14: Calculation errors of isolation displacement by using different damping models (PGA = $0.2 \mathrm{~g}$ ): (a) case 221, (b) case 222, (c) case 223, (d) case 224, (e) case 225, and (f) case 226. 
TABLE 11: Calculation schedule with PGA $=0.2 \mathrm{~g}$.

\begin{tabular}{lrr}
\hline Damping model & Frequency & Experimental case \\
\hline RD & $1 \& 2,1 \& 3$, and $1 \& 4$ frequencies of the isolated system & \\
NP-RD & $2 \& 3$ frequencies of the nonisolated system & Case 221-226 \\
CD & $1-4$ frequencies of the isolated system & E1, E2 \\
NP-CD & $1-3$ frequencies of the nonisolated system & \\
\hline
\end{tabular}

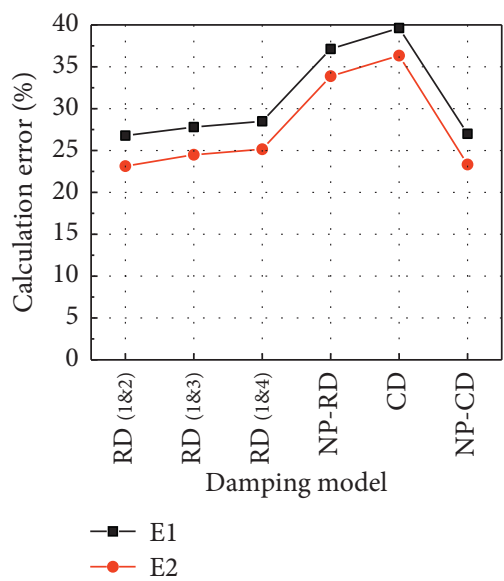

(a)

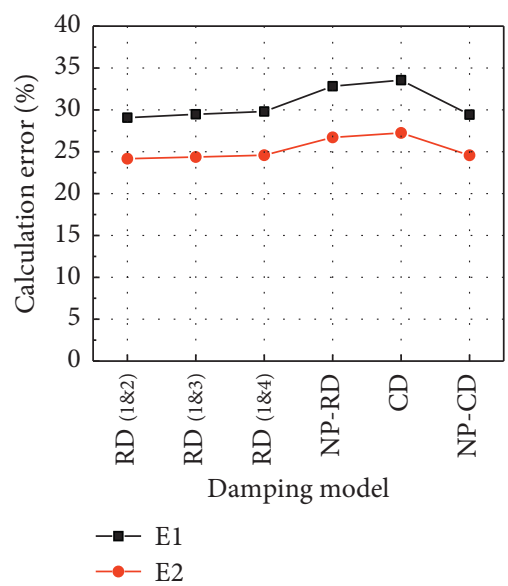

(d)

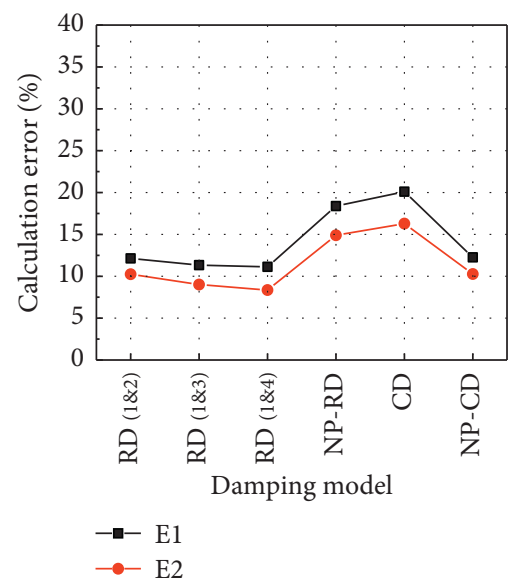

(b)

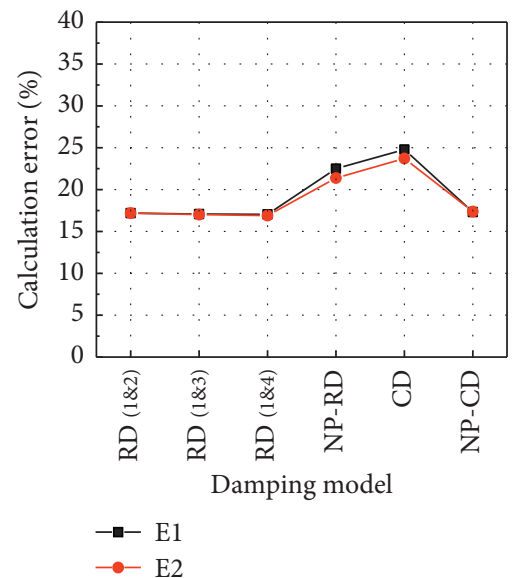

(e)

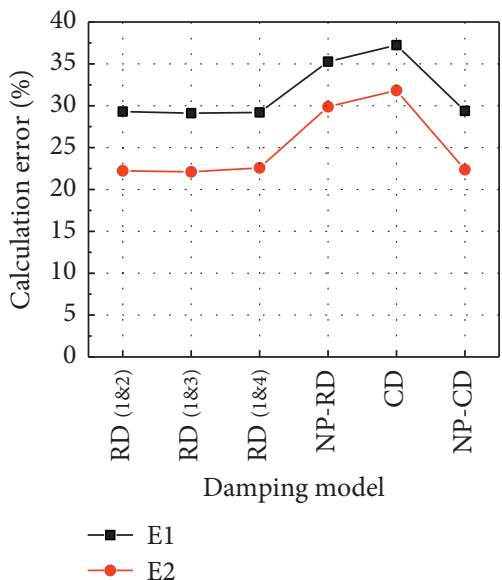

(c)

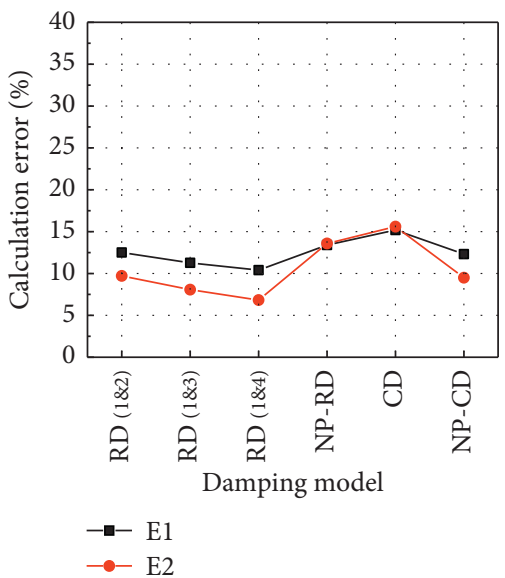

(f)

Figure 15: Calculation errors of the first story displacement by using different damping models (PGA = 0.2 g): (a) case 221, (b) case 222, (c) case 223, (d) case 224, (e) case 225, and (f) case 226.

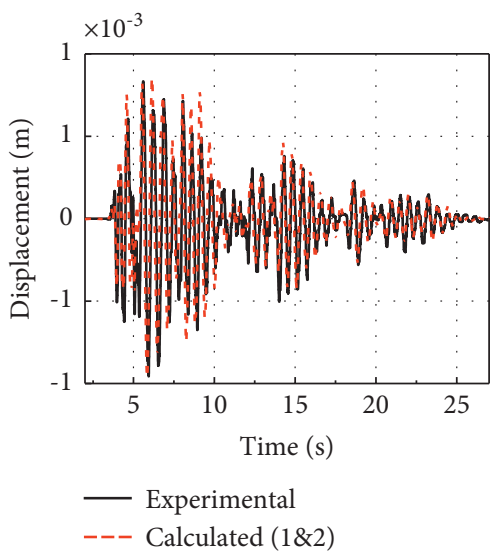

(a)

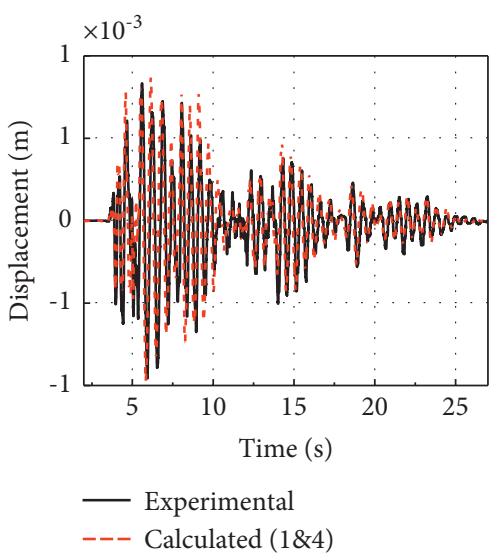

(b)

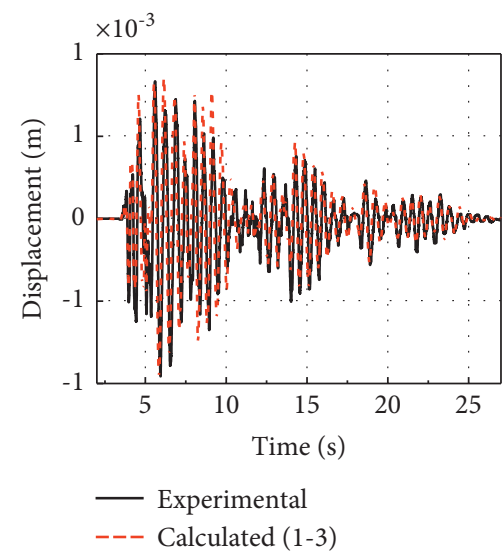

(c)

Figure 16: Displacement time histories of the first story by using different damping models (case 221): (a) RD with $1 \& 2$ frequencies of the isolated structure, (b) RD with 1\&4 frequencies of the isolated structure, and (c) NP-CD with 1-3 frequencies of the nonisolated structure. 


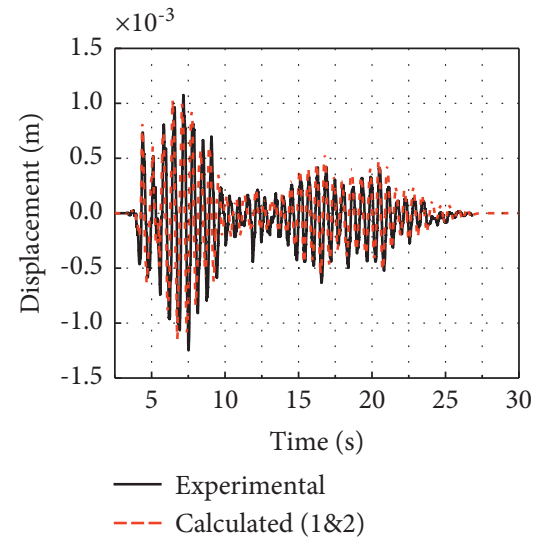

(a)

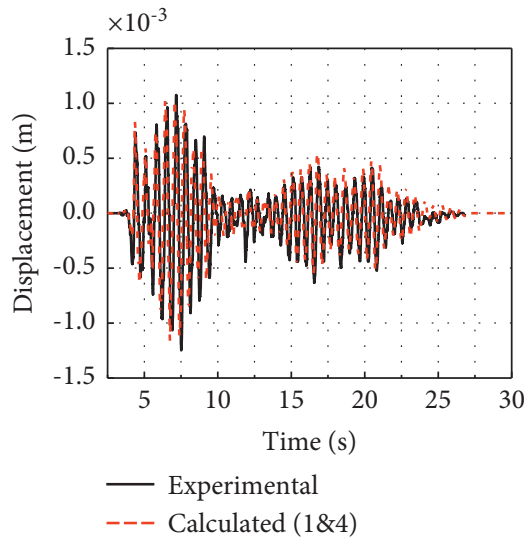

(b)

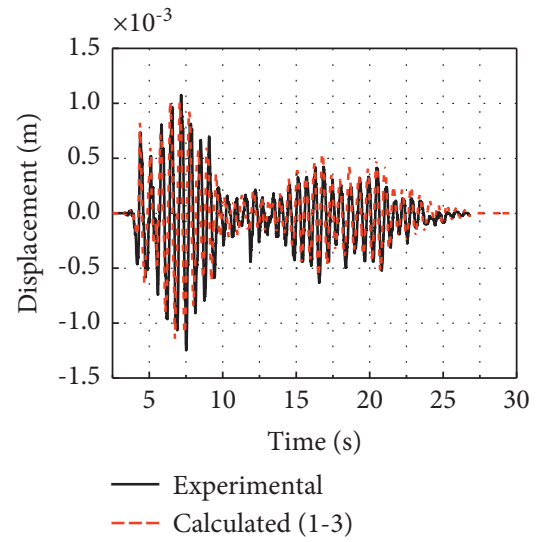

(c)

Figure 17: Displacement time histories of the first story by using different damping models (case 225): (a) RD with 1\&2 frequencies of the isolated structure, (b) RD with 1\&4 frequencies of the isolated structure, and (c) NP-CD with 1-3 frequencies of the nonisolated structure.

\section{Conclusions}

Frequency selection is researched on Rayleigh damping (RD) and nonproportional damping based on Rayleigh damping (NP-RD) in the dynamic calculation of the isolated structures. Serviceability of four damping models including $\mathrm{RD}, \mathrm{NP}-\mathrm{RD}, \mathrm{CD}$, and NP-CD is also studied by comparison of the calculations and tests. The conclusions are as follows:

(1) For the use of RD, the 1st and highest modal frequencies of the system are recommended in the dynamic calculation when the isolated structure is subjected to $\mathrm{PGA} \leq 0.2 \mathrm{~g}$

(2) For the use of NP-RD, the frequency selection of the superstructure does not matter, since the frequency of the isolation layer must be selected

(3) RD and NP-CD are firstly recommended to be used in the calculation of the isolated structure, followed by NP-RD and then CD

\section{Data Availability}

The experimental data used to support the findings of this study are available from the corresponding author upon request.

\section{Conflicts of Interest}

The authors declare that there are no conflicts of interest regarding the publication of this paper.

\section{Authors' Contributions}

Miao Han and Hongkai Du contributed equally to this work.

\section{Acknowledgments}

This research was funded by the China National Key R\&D Program during the 13th Five-Year Plan Period (Grant no. 2019YFC1509500) and Beijing Advanced Innovation Center for Future Urban Design, Beijing University of Civil Engineering and Architecture (Grant no. UDC2019032424).

\section{References}

[1] A. Bilbao, R. Avilés, J. Agirrebeitia, and G. Ajuria, "Proportional damping approximation for structures with added viscoelastic dampers," Finite Elements in Analysis and Design, vol. 42, no. 6, pp. 492-502, 2006.

[2] K. Y. Sanliturk and H. Koruk, "Development and validation of a composite finite element with damping capability," Composite Structures, vol. 97, pp. 136-146, 2013.

[3] C. W. Bert, "Material damping," Journal of Sound and Vibration, vol. 29, no. 2, pp. 129-153, 1973.

[4] X. T. Zhang, "Hypothesis on energy loss due to structural damping and its application to the vibration calculation," Journal of Vibration and Shock, vol. 1, no. 2, pp. 12-22, 1982.

[5] Z. Liang and G. C. Lee, "Representation of damping matrix," Journal of Engineering Mechanics, vol. 117, no. 5, pp. 1005-1019, 1991.

[6] S. Adhikari, "Damping modeling using generalized proportional damping," Journal of Sound and Vibration, vol. 293, no. 1-2, pp. 156-170, 2006.

[7] Z. M. Huang, S. L. Bai, and M. Lai, "Review on the damping in the earthquake response time-history analysis of structures," Journal of Earthquake Engineering and Engineering Vibration, vol. 16, no. 2, pp. 95-105, 1996.

[8] T. K. Caughey and M. E. J. O’Kelly, "Classical normal modes in damped linear dynamic systems," Journal of Applied Mechanics, vol. 32, no. 3, pp. 583-588, 1965.

[9] E. L. Wilson and J. Penzien, "Evaluation of orthogonal damping matrices," International Journal for Numerical Methods in Engineering, vol. 4, no. 1, pp. 5-10, 1972.

[10] D. R. Pant, A. C. Wijeyewickrema, and M. A. ElGawady, "Appropriate viscous damping for nonlinear time-history analysis of base-isolated reinforced concrete buildings," Earthquake Engineering \& Structural Dynamics, vol. 42, no. 15, pp. 2321-2339, 2013.

[11] D. G. Pan and L. L. Gao, "Comparison of determination methods for Rayleigh damping coefficients and effects on seismic responses of structures," Engineering Mechanics, vol. 32, no. 6, pp. 192-199, 2015. 
[12] C. Cruz and E. Miranda, "Evaluation of the Rayleigh damping model for buildings," Engineering Structures, vol. 138, no. 1, pp. 324-336, 2017.

[13] H. F. Wang, M. L. Lou, and R. L. Zhang, "Determining Rayleigh damping parameters for time history analysis of soil layers with deep deposit," Chinese Journal of Geotechnical Engineering, vol. 38, no. 3, pp. 468-476, 2016.

[14] E. Erduran, "Evaluation of Rayleigh damping and its influence on engineering demand parameter estimates," Earthquake Engineering \& Structural Dynamics, vol. 41, no. 14, pp. 1905-1919, 2012.

[15] B. F. Shorr and N. N. Serebryakov, "Numerical-experimental analysis of amplitude-dependent damping performances in components and materials," Journal of Machinery Manufacture and Reliability, vol. 41, no. 14, pp. 272-279, 2011.

[16] M. R. Hajiabadi and V. Lotfi, "An effective approach for utilizing damping solvent extraction method in frequency domain," Soil Dynamics and Earthquake Engineering, vol. 38, pp. 46-57, 2012.

[17] N. Yoshida, S. Kobayashi, I. Suetomi, and K. Miura, "Equivalent linear method considering frequency dependent characteristics of stiffness and damping," Soil Dynamics and Earthquake Engineering, vol. 22, no. 3, pp. 205-222, 2002.

[18] D. G. Pan, "An optimization method for the direct determination of Rayleigh damping coefficients," Engineering Mechanics, vol. 30, no. 9, pp. 16-21, 2013.

[19] R. E. Spears and S. R. Jensen, "Approach for selection of Rayleigh damping parameters used for time history analysis," Journal of Pressure Vessel Technology, vol. 134, no. 9, p. 7, Article ID 061801, 2012.

[20] J. E. Luco, “A note on classical damping matrices," Earthquake Engineering \& Structural Dynamics, vol. 37, no. 4, pp. 615626, 2008.

[21] C. B. Hu, Y. G. Wang, and D. S. Ling, "Physical essence and influence of model parameters on dynamic response of Rayleigh damping," Journal of Zhejiang University (Science Edition), vol. 51, no. 7, pp. 1284-1290, 2017.

[22] T. K. Caughey, "Classical normal modes in damped linear dynamic systems," Journal of Applied Mechanics, vol. 27, no. 2, pp. 269-271, 1960.

[23] M. L. Lou, S. Kang, and L. Yin, "Shaking table test on damping effect," Journal of Tongji University(Natural Sciences), vol. 40, no. 3, pp. 402-407, 2012.

[24] D. Pan and C. Li, "A constrained optimization solution for Caughey damping coefficients in seismic analysis," Engineering Computations, vol. 34, no. 3, pp. 682-708, 2017.

[25] A. Lanzi and J. E. Luco, "Caughey damping series in terms of products of the flexibility matrix," Journal of Engineering Mechanics, vol. 143, no. 9, p. 9, Article ID 04017089, 2017.

[26] F. Shen and M. L. Lou, "Influence of high modes of super high-rise building on its seismic responses," Engineering Mechanics, vol. 29, no. S1, pp. 23-28, 2012.

[27] M. L. Lou and J. Zhang, "Discussion on damping models for seismic response analysis of long-span bridge," Journal of Vibration and Shock, vol. 28, no. 5, pp. 22-26, 2009.

[28] M. Abbasi and M. A. Moustafa, "Effect of damping modeling and characteristics on seismic vulnerability assessment of multi-frame bridges," Journal of Earthquake Engineering, vol. 25, pp. 1-28, 2019.

[29] Q. Sun and D. Dias, "Significance of Rayleigh damping in nonlinear numerical seismic analysis of tunnels," Soil Dynamics and Earthquake Engineering, vol. 115, pp. 489-494, 2018.
[30] K. L. Ryan and J. Polanco, "Problems with Rayleigh damping in base-isolated buildings," Journal of Structural Engineering, vol. 134, no. 11, pp. 1780-1784, 2008.

[31] M. Han, Y. J. Zhang, and H. K. Du, "Test study on shear performance of small laminated rubber bearing," Earthquake Resistant Engineering and Retrofitting, vol. 39, no. 2, pp. 111-116, 2017.

[32] D. G. Pan, X. Q. Fu, Q. J. Chen, L. Pan, and J. Tan, “A modal perturbation method for eigenvalue problem of non-proportionally damped system," Applied Sciences, vol. 10, no. 1, p. 341, 2020.

[33] D. De Domenico and G. Ricciardi, "Dynamic response of non-classically damped structures via reduced-order complex modal analysis: two novel truncation measures," Journal of Sound and Vibration, vol. 452, pp. 169-190, 2019.

[34] D. De Domenico, G. Falsone, and G. Ricciardi, "Improved response-spectrum analysis of base-isolated buildings: a substructure-based response spectrum method," Engineering Structures, vol. 162, pp. 198-212, 2018.

[35] J. Xu, "A synthesis formulation of explicit damping matrix for non-classically damped systems," Nuclear Engineering and Design, vol. 227, no. 2, pp. 125-132, 2003.

[36] H. Anajafi, R. A. Medina, and E. Santini-Bell, "Effects of the improper modeling of viscous damping on the first-mode and higher-mode dominated responses of base-isolated buildings," Earthquake Engineering \& Structural Dynamics, vol. 49, no. 1, pp. 51-73, 2020.

[37] B. H. Yin, M. Q. Wang, and X. D. Wu, "Decay method for measuring structural vibration damping," Journal of Vibration and Shock, vol. 33, no. 4, pp. 100-106, 2014.

[38] B. C. Bloss and M. D. Rao, "Estimation of frequency-averaged loss factors by the power injection and the impulse response decay methods," Journal of the Acoustical Society of America, vol. 117, no. 1, pp. 240-249, 2005.

[39] Y. Du, H. Li, and B. F. Spencer, "Effect of non-proportional damping on seismic isolation," Journal of Structural Control, vol. 9, no. 3, pp. 205-236, 2002. 